\title{
Unethical Behavior and Group Identity in Contests*
}

\author{
Julien Benistant ${ }^{\dagger}$ and Marie Claire Villeval ${ }^{\ddagger}$
}

March 3, 2019

\begin{abstract}
Using a real-effort experiment, we study whether group identity affects unethical behavior in a contest game. We vary whether minimal group identity is induced or not, whether individuals have to report their own outcome or the outcome of their competitor, and whether pairs of competitors share the same group identity or not. We show that individuals misreport in the same proportion and to the same extent by inflating their outcome or by decreasing their opponent's outcome, except when any possible scrutiny by the experimenter is removed. Regardless of the possibility of scrutiny by the experimenter, misreporting is affected neither by the competitor's group identity nor by the individual's beliefs about others' misreporting behavior. This suggests that in competitive settings, unethical behavior is mainly driven by an unconditional desire to win.
\end{abstract}

Keywords: Lying, sabotage, group identity, competition, experiment.

JEL Codes: C92, M54, D63.

*Acknowledgments: We thank Arno Riedl, Shaul Shalvi and Benedikt Herrmann for helpful discussions. We are grateful to participants at the 2017 ESA European Meeting in Vienna, the 2017 ASFEE conference, the Cortex Student Club, the GATE-Lab seminar, and the Toulouse-Lyon BEE workshop for useful comments. We also thank Quentin Thevenet for programming assistance. This research has been funded by a grant of the French National Research Agency (ANR, FELIS Grant, ANR-14-CE280010-01) and by the LABEX CORTEX (ANR-11-LABX-0042) of Université de Lyon within the program "Investissements d'Avenir" (ANR-11-IDEX-007) operated by the French National Research Agency. J. Benistant thanks the Fondation pour la Recherche Médicale for financial support (FDT20170436847).

${ }^{\dagger}$ Univ Lyon, Université Lumière Lyon 2, GATE, UMR 5824, F-69130 Ecully, France. benistant@gate.cnrs.fr

${ }_{\ddagger}^{\ddagger}$ Univ Lyon, CNRS, GATE, UMR 5824, F-69130 Ecully, France; IZA, Bonn, Germany; villeval@gate.cnrs.fr 


\section{Introduction}

Based on 2,410 cases of occupational fraud collected between January 2014 and October 2015 the Association of Certified Fraud Examiners (ACFE, 2016) estimates that unethical behavior in organizations leads to a loss of about US $\$ 6.3$ billion. Occupational fraud is a scourge for any organization, as it may discourage honest effort and ruin the reputation of a company if uncovered. Dishonesty in organizations may depend on the presence of "bad apples" (e.g., Gino et al., 2009), but also on the institutional environment, including weak societal norms (e.g., Gächter and Schulz, 2016), corporate cultures encouraging materialistic values (e.g., Cohn et al., 2014), and competitive schemes (e.g., Shleifer, 2004; Falk and Szech, 2013). Competitive incentives aim at motivating employees (Tullock, 1980; Lazear and Rosen, 1981) but may generate sabotage, as shown both theoretically (Lazear, 1989; Konrad, 2000) and empirically (e.g., Harbring et al., 2007; Carpenter et al., 2010; Harbring and Irlenbusch, 2011; Kilduff et al., 2016; Feltovich, 2018); cheating opportunities may lead less honest people to self-select into more competitive payment schemes (Faravelli et al., 2015).

The prevalence of unethical behavior in competitive settings varies with the intensity of competition (e.g., Schwieren and Weichselbaumer, 2010; Harbring and Irlenbusch, 2011; Cartwright and Menezes, 2014; Conrads et al., 2014) or the outcome of a previous competition (Pittarello et al., 2013; Banerjee et al., 2018; Schurr and Ritov, 2016). Among these environmental factors, one can suspect that the strength of preexisting links between potential competitors in a group may affect the prevalence of unethical behavior. For example, an employee who competes for a promotion against one of his team members may be less likely to behave unethically than when faced with an employee from another, more distant, group. Our main research objective in this paper is to identify the influence of group identity and social distance between competitors on unethical behavior in competitive settings.

Specifically, we study whether the social identity of their opponent in a competition affects individuals' willingness to misreport an outcome that contributes to determining 
their payoff. Are people less willing to misreport in order to increase their chance of winning a competition when doing so harms an in-group? On the other hand, are they more willing to misreport when cheating harms an opponent from another group? We also examine whether group identity has a different impact, if any, when individuals have to report their own outcome and when they have to report their opponent's outcome to determine who is the winner.

By connecting the literature on group identity, on competitive behavior and on lying, our contribution is threefold. First, we complement the economic analysis of the role of group identity (Tajfel and Turner, 1979; Akerlof and Kranton, 2000) in social interactions by examining the influence of social identification on unethical behavior. Studies of group identity and cooperation have shown the importance of in-group favoritism, i.e., people treat more generously someone who shares the same group identity than someone who belongs to another social group (e.g., Charness et al., 2007; Chen et al., 2009; Goette et al., 2012). ${ }^{1}$ Much less research has been conducted on the importance of group identity in competitive settings (e.g., Datta Gupta et al., 2013; Chen et al., 2015; Chowdhury et al., 2016; Kato et al., 2016). ${ }^{2}$ Our contribution to this literature is exploring the impact of group identity on unethical behavior.

Second, we contribute to the understanding of lying behavior by studying how group identity affects individuals' unethical behavior. The previous literature has shown that priming group identity increases the prevalence of norm violation when identity is asso-

\footnotetext{
${ }^{1}$ In-group favoritism relaxes punishment toward out-groups (Bernhard et al., 2006; Goette et al., 2012); it positively affects coordination (Efferson et al., 2008), trust and reciprocity (Buchan and Croson, 2004; Hargreaves Heap and Zizzo, 2009), generosity in dictator games (Güth et al., 2009), cooperation in ultimatum bargaining games (Mcleish and Oxoby, 2011) and in dilemma games such as public goods games (Eckel and Grossman, 2005), common-pool resource games (Ruffle and Sosis, 2006), and prisoner dilemma games (Goette et al., 2006; Charness et al., 2007; Guala et al., 2013; Li and Liu, 2017), as well as the willingness to preserve other's image at a cost (Eriksson et al., 2017). When they interact with ingroups, individuals trust more, reciprocate more, contribute more to public goods, and cooperate more. The other side of the medal is that when they interact with out-groups, they are usually less cooperative (e.g., Mcleish and Oxoby, 2011; Chen et al., 2014).

${ }^{2}$ Datta Gupta et al. (2013) report that choosing the gender of a potential competitor influences competitiveness. Chen et al. (2015) find that a salient group identity stiffens the competition between different universities. Chowdhury et al. (2016) show that a more salient group identity (natural vs. minimal) escalates conflicts in a contest by motivating people to increase their effort. Kato et al. (2016) report that co-workers sharing a common group identity do not react to competitive monetary incentives whereas co-workers with different group affiliation compete more aggressively.
} 
ciated with weaker morality (Cohn et al., 2015) or stronger materialistic values (Cohn et al., 2014). Studying fairness-restorative dishonesty across games, Della Valle and Ploner (2017) show that being treated unfairly by an out-group peer in a dictator game increases dishonesty in a subsequent mind game compared to a baseline treatment without social identity, whereas dishonesty is unaffected by the unfair decision of an in-group dictator. In contrast, we investigate a competitive setting where dishonest reporting is not at the cost of the experimenter but at the expense of the opponent. ${ }^{3}$ Some studies have found evidence of in-group favoritism in deceptive behavior (e.g., Jiang, 2015; Cadsby et al., 2016; Chakravarty and Maximiano, 2016), but results are contrasted. ${ }^{4}$ Hruschka et al. (2014) showed that behaving dishonestly to favor in-groups instead of following an impartial rule is more likely in societies with lower institutional effectiveness. Our contribution is considering how competitive incentives affect the impact of group identity on unethical behavior in a setting where both competitors can cheat.

Finally, we contribute to the analysis of ethics in competition. As mentioned above, several studies have shown, theoretically and empirically, that some people bend their moral rules to increase their chance of winning a competition, for example through sabotage (e.g., Harbring and Irlenbusch, 2011; Harbring et al., 2007; Chowdhury and Gürtler, 2015). But we know little about whether sabotaging a competitor is morally equivalent to cheating on one's own performance, when both actions similarly increase one's chance of winning. Rigdon and D'Esterre (2015) found that individuals are more likely to cheat by overreporting their own performance than by underreporting their opponent's performance under both competitive and noncompetitive incentives. Lying about an op-

\footnotetext{
${ }^{3}$ Moreover, in our experiment the ex ante inequality of chances in the contest results from differences in ability levels and in luck, not from the selfishness of another player, as explained below; fairnessrestorative dishonesty should only emerge when the subject anticipates that his opponent will cheat. Finally, in our main treatments lying can be measured at the individual level and we use a mind game as a robustness test.

${ }^{4}$ Jiang (2015) and Cadsby et al. (2016) report that in a noncompetitive environment, subjects are more willing to lie when lying benefits a member of their group compared to when it benefits a member of another group. Similarly, cheating is lower when it harms another student compared to when cheating is at the expense of the experimenter (Meub et al., 2016). Using a sender-receiver game with a natural group identity based on friendship, Chakravarty and Maximiano (2016) showed that deception is less likely when the receiver is a sender's friend. In contrast, using the same game Feldhaus and Mans (2014) found that the sender's decision to deceive the receiver is independent of whether they share the same group identity or not.
} 
ponent's outcome increases the moral cost of lying compared to lying about one's own outcome. We try to replicate this finding and test whether inducing group identity amplifies this effect when the opponent is an in-group and cancels it out when the opponent is an out-group. ${ }^{5}$

To sum up, the novelty of our approach is studying the impact of group identity on dishonesty in competitive settings. ${ }^{6}$ In a repeated two-player Tullock contest, the relative final scores of the players determine their probability of winning the contest. The final score of a player is the sum of his performance in a real-effort task and a random number that could represent his idiosyncratic environmental working conditions. After performing the task, subjects are informed of their performance and their number, and of the performance and the number of their opponent. We vary within-subjects which information players have to report. In one condition, they have to report their own random number ("Self-condition"), while in the other they have to report their opponent's number ("Opp-condition"). ${ }^{7}$ When reporting, subjects were able to inflate their own number or to deflate their opponent's number, ${ }^{8}$ depending on the condition, at no risk of detection by the opponent due to the use of a probabilistic contest. We manipulated between-subjects the existence of group identity in two main treatments. In the No-Identity treatment, no identity is induced. In the Identity treatment, a minimal identity is induced following the

\footnotetext{
${ }^{5}$ Note that people motivated by social status may behave competitively even without competitive monetary incentives. Charness et al. (2014) showed that individuals cheat more by artificially increasing their own performance than by sabotaging group members to improve their performance rank under a flat-payment scheme. In contrast, we introduce competitive incentives and no monetary cost for lying.

${ }^{6}$ In a lab-in-the-field experiment in rural India, (Banerjee et al., 2018) showed that high-caste individuals are more likely to lie to increase their payoffs while harming a member from the backward caste when they learn that they have lost a tournament under a quota policy protecting backward caste members. However, in this study the opportunity to lie follows a distinct tournament game. In contrast, we introduce an opportunity to lie in a contest.

${ }^{7}$ Reporting on behalf of another employee is typical of the 360-degree feedback in which each employee rates other employees (team members, subordinates, and supervisors). Over one-third of U.S. companies use this type of feedback (see Bracken et al., 2001). An advantage of multi-rater feedback is that managers can collect information that they would not be able to obtain by looking directly at quantitative outputs (see Lepsinger and Lucia, 2009, e.g.,). This can include the idiosyncratic shocks that we intend to capture with our random numbers. The reliability of such feedback has been questioned because of possible manipulations and a lack of transparency (on the U.S. Department of Foreign Affairs, see Bent (2018); on Amazon, see Kantor and Streitfeld (2015)). Note, however, that these schemes are used for development and indirectly for hiring and promotion.

${ }^{8}$ Lying in the Opp-condition is similar to sabotage. Compared to other papers, however, sabotage is not modelled as an effort with a monetary cost; here, misreporting involves only a moral cost.
} 
procedure developed in Chen et al. (2009). According to the case subjects are matched with a player who shares the same identity or with a subject with the other identity.

Our results show that $53.7 \%$ of the subjects misreport at least once and when they lie, they do it to the full extent. Contrary to our conjecture, in both treatments they misreport their opponent's outcome as often and by as much as when they misreport their own outcome. We find no effect of group identity on misreporting: there is no effect from social distance between the individual and his opponent on the frequency, the intensity, and the nature of lies. Although they express in-group favoritism in distributive choices and although they believe that group identity affects others' misreporting behavior, people do not lie less against an in-group than an out-group opponent, or in the absence of group identity. The absence of difference could be driven by the fact that the experimenter knows the truth: those who misreport in this environment may be less sensitive to social image and less sensitive to group identity. Therefore, we conducted an additional treatment in which scrutiny is eliminated by using a mind game. In this new treatment subjects report higher outcomes in the Self-condition than in the Opp-condition in absolute value (as in Rigdon and D'Esterre, 2015) but group identity remains insignificant. These results suggest that in competitive settings, unethical behavior is mainly driven by an unconditional desire to win.

The next section introduces our experimental design and the procedures. Section 3 outlines our behavioral conjectures. Sections 4 and 5 report our results and those from robustness tests, respectively. Finally, section 6 discusses these results and concludes.

\section{Experimental Design and Procedures}

We first introduce our experimental design for the main treatments and then, the procedures. 


\subsection{Experimental Design}

Our experiment is based on a two-player contest played for 16 periods with a reshuffling of pairs after each period. The probability of each pair member winning the contest depends on a comparison of the two pair members' scores. A score is defined as the sum of the performance in a real-effort task and of an idiosyncratic random number that subjects have to report, as explained below. We implemented a $2 \times 2$ mixed factorial design. One dimension varies within-subjects whether the individual has to report his own random number ("Self-condition") or his opponent's number ("Opp-condition"). The Self- and Opp-conditions were implemented over eight periods each, and were presented in a totally randomized order across periods. The other dimension varies between-subjects the presence of group identity in two treatments, namely the Identity treatment and the No-Identity treatment. We describe each treatment first and then, the additional measures collected in the experiment.

\subsubsection{No-Identity Treatment}

The competition game consists of a two-player Tullock-lottery contest in which two subjects are paired and compete against each other to win a prize. The outcome of the contest depends on the relative final scores. In each period $t$, the probability to win of a given subject $i$ matched with a subject $j$ is given by the following formula:

$$
p_{i t}(\text { win })=\frac{\text { Finalscore }_{i t}}{\text { Finalscore }_{i t}+\text { Finalscore }_{j t}}
$$

The higher the subject's final score relative to that of his opponent, the higher is his probability of winning. The winner receives 100 ECUs (Experimental Currency Units) and the loser 50 ECUs. The final score of a subject is the sum of his performance (the "subscore") in a real-effort task and an idiosyncratic random number. The task is an encryption task, as in Erkal et al. (2011) and Charness et al. (2014). It consists of decoding letters into numbers within 30 seconds with the help of a correspondence table displayed on the computer screen. In our design, each problem is composed of one letter only. Subjects have to enter the corresponding number and to validate their answer. They receive immediate feedback on whether their answer was correct or not. If the answer was 
not correct, they have to enter a new number. If the answer was correct, another letter is displayed on the screen. The subscore for the period is the total number of correct answers provided within 30 seconds.

Once the 30 seconds have elapsed, subjects are informed both of their own subscore and of their opponent's subscore. Then, the program draws two random numbers independently from a uniform distribution in the interval $[-5,5]$, one for the subject and one for his opponent, with rebate between the two draws. These numbers can represent the environmental conditions in which the task has to be performed (for example, the environmental conditions that influence the success of a project, the quality of the managers in charge of different units, ...). Subjects are informed of these two numbers. The rest of the period depends on the condition and subjects are informed on the condition prevailing in the period after they have performed the task.

In the Self-condition, subjects have to report their own random number in the computer. In the Opp-condition, they have to report instead their opponent's number. Subjects who are willing to increase their chance of winning the prize have the opportunity to misreport their own or their opponent's random number, depending on the condition. In the instructions, nothing was mentioned about this possibility. The reported number is added to the subscore to determine the final score.

Finally, the outcome of the contest is computed according to equation 1 and subjects are informed whether or not they won the prize. They are only reminded of their final score in the Self-condition or their opponent's final score in the Opp-condition. Indeed, to avoid the contamination of lying and blind revenge, players are not informed whether their own number was reported truthfully or not in the Opp-condition, or whether the opponent misreported his own number or not in the Self-condition. In no condition do they learn the distance between their own final score and their opponent's final score. To determine the subjects' earnings in this part, two periods (one in each condition) were randomly selected at the end of the session, and the payoffs in these periods were added up. 


\subsubsection{Identity Treatment}

The Identity treatment is similar to the No-Identity treatment, except that group identity is induced prior to the contest game. The identity induction part is composed of three stages, as described by Chen et al. (2009). The first two stages aim at inducing identity, while the third one serves to assess the validity of identity manipulation.

In the first stage, subjects have to review five pairs of paintings by Klee and Kandinsky. Without receiving any clue about the painters, they report their preferred painting in each pair. According to their preferences toward one or another painter, they are split into two groups, the "Klee group" and the "Kandinsky group". Unlike Chen et al. (2009), we form groups of equal size to get a balanced matching in the contests. Subjects with the weakest preference toward one artist or another are switched into the other group, if needed. The whole procedure is made common knowledge. Subjects are privately informed of their group affiliation.

In the second stage, subjects have to review two additional paintings and they are asked to identify which artist painted each of them. Before entering their answers individually, they have the opportunity to participate in a chat discussion over eight minutes, exclusively with their group members. The aim is to reinforce the feeling of belonging to a group, since the chat allows group members to help each other. Each correct answer pays 50 ECUs.

The third stage consists of five periods of a third-party allocation task. Subjects have to share a number of ECUs between two anonymous participants. They are not allowed to allocate ECUs to themselves. The objective is to identify in-group favoritism in the allocation decisions. From the first period up to the fifth, the number of ECUs to be allocated increases from 50 to 250 by increments of 50 ECUs. In each period, subjects are presented three scenarios. In the first scenario, the two participants share the same group identity as the decision-maker. In the second scenario, the two participants belong to the other group. In the third scenario, one participant belongs to the same group and 
the other one belongs to the other group. ${ }^{9}$

After completion of the third stage, subjects play the contests. The rules are the same as in the No-Identity treatment, except that subjects are informed of the group identity of their opponent in each period after performing the task. In half of the 16 periods, subjects face an opponent from their group (Same Group, or "SG pairs" hereafter). In the other half, they face an opponent from the other group (Other Group, or "OG pairs" hereafter). Thus, the Identity treatment includes four sets of four periods: SG pairs in the Self-condition, SG pairs in the Opp-condition, OG pairs in the Self-condition and OG pairs in the Opp-condition. The order between these four conditions was totally random across periods.

\subsubsection{Additional Measures}

\section{Belief Elicitation}

Some subjects may misreport because of their preference or because they believe that their opponent will not report truthfully (e.g., López-Pérez and Spiegelman, 2013). At the end of the contest game, we elicited the subjects' beliefs about the frequency of misreports in previous sessions. In the No-Identity treatment, subjects are presented two scenarios based on the same contest game. In the first scenario, two participants, A and $\mathrm{B}$, have to report their own random number, with participant A having a higher subscore than participant B. Subjects have to indicate how many A participants among 10 and how many B participants among 10 randomly selected in previous sessions they think misreported their random number. In the second scenario, participants A and B have to report their opponent's number. Similarly, subjects have to indicate how many A participants among 10 and how many participants B among 10 they think misreported the random number of their opponent. In the Identity treatment, subjects have to guess how many A and B participants out of 10 drawn from past sessions misreported in four scenarios: in two scenarios A and B share the same group identity, and in the two other

\footnotetext{
${ }^{9}$ The procedure for payment followed Chen et al. (2009). We generated a random sequence of ID numbers. Subjects allocated ECUs between the two participants whose ID directly followed their own ID in the sequence. Accordingly, a subject's payoff was the sum of the ECUs allocated to him by the two people whose ID preceded him in the sequence.
} 
scenarios they belong to different groups. One of these guesses was randomly selected for payment. A correct guess paid 100 ECUs. ${ }^{10}$

\section{Online Questionnaire on Social Preferences}

Since the outcome of the contest leads to very unequal payoffs, the players' social preferences may have affected their behavior in our experiment. Therefore, about a week prior to the session in the laboratory, subjects had to fill out an incentivized online questionnaire. The main part of this questionnaire consists of the Social Value Orientation (SVO) test of Murphy et al. (2011). In this test subjects face six decisions successively. Each decision consists of choosing an allocation of ECUs between himself and another participant among nine options. Figure C.1, in the Appendix C, shows the first decision in the test. For this decision, the first option offers an equal split (85 ECUs for oneself and for the other), and the degree of inequality increases between the second and the ninth option (up to 85 ECUs for oneself and 15 ECUs for the other). The other five decisions have the same structure. The subject's six decisions allow us to compute an index, called the SVO angle, for each subject. ${ }^{11}$ The lower this index is, the less pro-social the subject is.

At the beginning of the questionnaire, subjects are informed that one of their six decisions will be randomly selected and that they will be matched twice with another subject participating in the same laboratory session. In the first matching, the subject is paid the amount he allocated to himself and the matched partner is paid the amount the subject allocated to the other. In the second matching, the subject is paid according to the choice made by the matched partner for the other and this matched partner receives the amount he allocated to himself. Feedback on the earnings in this task is given only at the end of the lab session.

\footnotetext{
${ }^{10} \mathrm{We}$ acknowledge that some liars may exaggerate their estimate of the others' willingness to misreport to self-excuse their own misbehavior. We have tried to minimize this bias by incentivizing the belief elicitation but we cannot exclude it. Alternatively, eliciting beliefs prior to the competition game would have attracted the attention of the subjects on the lying opportunity and probably introduced an experimenter demand effect.

${ }^{11}$ We compute the mean allocation that the subject chose for himself and the mean allocation he chose for the other. Then, we subtract 50 from each of these means. Finally, the inverse tangent of the ratio between these means is computed, resulting in the SVO index.
} 


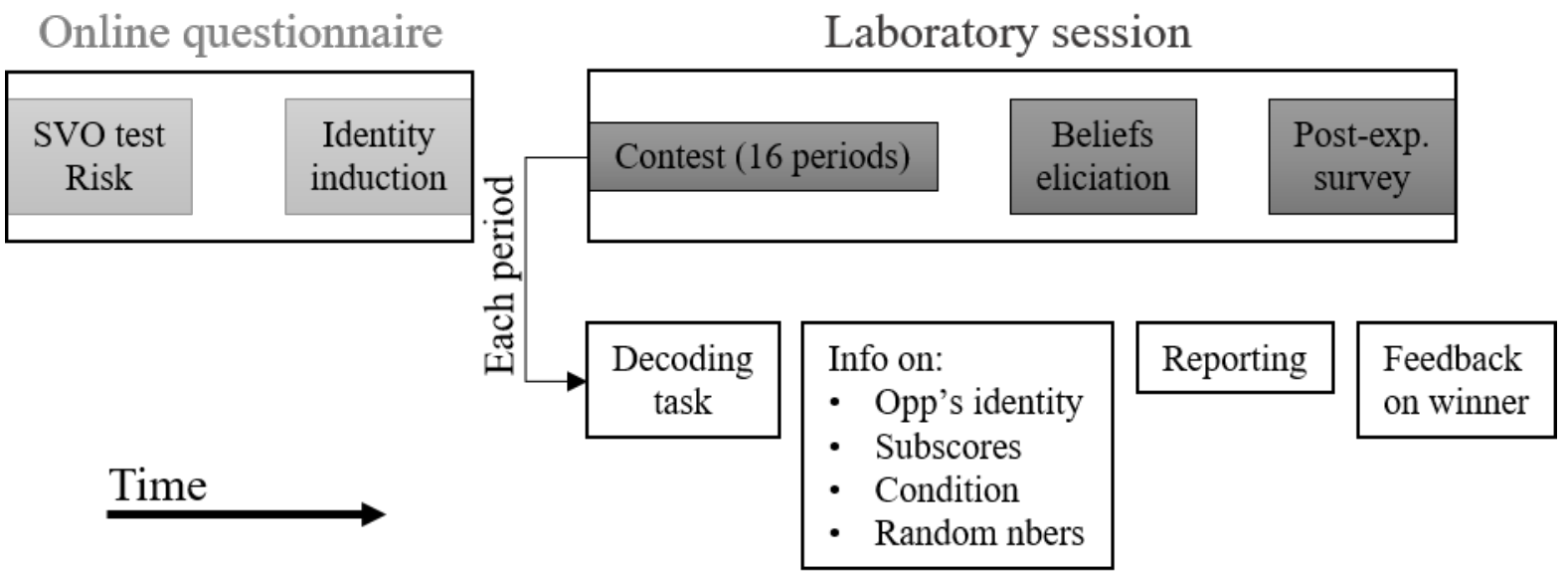

Figure 1: Timeline of the experiment

In addition to the SVO test, subjects have to answer ten questions taken from the riskelicitation questionnaire by Weber et al. (2002) with no other objective than diverting the subjects' attention from the elicitation of social preferences in the experiment. Figure 1 summarizes the timeline of the experiment.

\subsection{Procedures}

The experiment was conducted at GATE-Lab, Lyon (France). 192 subjects were recruited using HROOT (Bock et al., 2014). 77.60\% of the subjects were students from local engineering, business, and medical schools. We conducted four sessions of the No-Identity treatment with 64 subjects and eight sessions of the Identity treatment with 128 subjects. Table B.1 in the Appendix B summarizes the participants' characteristics, with no significant difference between treatments. The online questionnaire was programmed with LimeSurvey (Limesurvey $\mathrm{GmbH}$ ) and the laboratory experiment with Z-tree (Fischbacher, 2007). In the lab sessions, instructions were distributed to the subjects and read aloud (see Appendix A). In the Identity treatment we first distributed the instructions describing the first two stages of the group identity induction procedure. The instructions for the third stage were distributed only after these two stages were completed. The instructions used neutral language. Those for the belief elicitation were displayed directly on the screens at the end of the contest game. 
Sessions lasted on average 70 minutes for the No-Identity treatment and 90 minutes for the Identity treatment. Someone who was not aware of the content of the experiment paid participants in private in a separate room. This was made clear in the instructions. ECUs were converted into Euros, at the rate of 100 ECUs to $€ 2.50$. Mean earnings were $€ 19.29(\mathrm{SD}=1.78)$, including a $€ 5$ show-up fee and an average $€ 1.57$ ( $\mathrm{SD}=0.52$ ) for the online task.

\section{Behavioral Conjectures}

Since there is no monetary cost for lying, individuals who are willing to maximize their earnings and have no moral cost for lying should misreport to the full extent to maximize their probability of winning the contest, regardless of their performance at the task and of their random number. In contrast, individuals who suffer a finite moral cost from lying should be less likely to misreport or should misreport only partially, and those who endure an infinite cost of lying should never misreport. This conjecture relies on the recent literature on lying (e.g., Mazar et al., 2008; Fischbacher and Föllmi-Heusi, 2013; Gibson et al., 2013; Kajackaite and Gneezy, 2017; Abeler et al., 2019) showing that dishonesty is usually partial.

In contexts in which they have to report performance or outcomes, individuals who are willing to maximize their payoffs should misreport to the same extent (albeit not in the same direction) their outcome and the outcome of their opponent. However, Rigdon and D'Esterre (2015) have found evidence that individuals misreport more their own performance than the performance of another person, in both competitive and noncompetitive settings. Similarly, we conjecture that in our experiment subjects are more likely to overreport their own number than underreport their opponent's number, because harming directly another person may be perceived as aggressive. We summarize our first conjecture as follows:

Conjecture 1 (Misreporting): (a) Subjects misreport both their own number and their opponent's number; and (b) they are more likely to overreport their number than underreport the opponent's number. 
Previous literature has shown that people who identify with a social group tend to favor their in-group members in terms of cooperation, trust and reciprocity compared to out-group (Goette et al., 2006; Charness et al., 2007; Chen et al., 2009). In-group favoritism can come with out-group aggressiveness even without any strategic consideration (parochial altruism) (Abbink et al., 2012; Goette et al., 2012; Kolmar and Wagener, 2012). Accordingly, we anticipate that the moral cost of lying is higher when the victim of the lie is an in-group, and lower when it is an out-group. Thus, we expect subjects to be less likely to misreport when they are paired with an in-group (or more with an out-group) in the Identity treatment, especially in the Opp-condition.

Finally, in-group favoritism can originate from two main channels: preferences and beliefs about how others will behave. Previous studies on group identity and distributive choices (e.g., Yamagishi and Mifune, 2008; Güth et al., 2009; Ockenfels and Werner, 2014), or cooperation (Guala et al., 2013) favor the role of beliefs. Thus, we conjecture that subjects believe that in-group opponents are less likely to lie than out-group opponents. As a result and regardless of preferences, they may deceive less when matched with an in-group and more when matched with an out-group. Thus, we conjecture that pairs composed of in-groups are less likely to misreport (or more if composed of out-groups). Our second conjecture is the following:

Conjecture 2 (Social identity and misreporting): (a) When facing an in-group opponent, subjects misreport less than when facing an out-group opponent, especially in the Oppcondition; and (b) differentiated beliefs about the opponent's behavior according to his group identity are correlated with reporting behavior.

\section{Results}

In this section we focus exclusively on reporting behavior. Indeed, a separate analysis of the subject's performance reveals no significant difference in the subscores between condi- 
tions. ${ }^{12}$ We start by presenting general results on reporting behavior under the different conditions. Next, we analyze the impact of group identity on misreporting. Finally, we examine the relationship between the subjects' beliefs and their reporting behavior.

\subsection{Misreporting behavior across conditions}

We introduce our first result:

Result 1: (a) More than half of the subjects misreport self-interestedly at some point, and those who misreported did it to the full extent most of the time. (b) They misreported to the same extent and with the same frequency when they reported for themselves (Selfcondition) or for their opponent (Opp-condition).

Result 1 gives some support to Conjecture 1a but rejects Conjecture 1b.

Support for Result 1. Figures $2 \mathrm{a}$ and $2 \mathrm{~b}$ display the distribution of numbers reported by the subjects in the Self-condition and in the Opp-condition, respectively, by treatment.

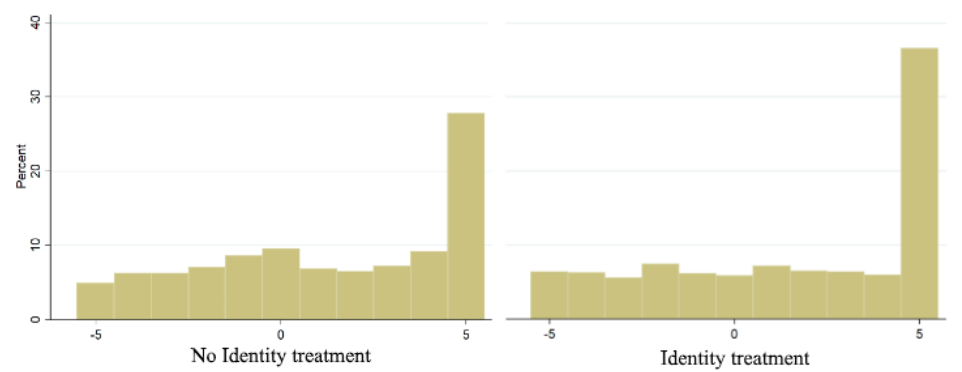

Figure 2a: Distribution of numbers reported in the Self-condition, by treatment

\footnotetext{
${ }^{12}$ For non-parametric statistics, we consider the averages at the session level.we consider only the first period. Two-sided Wilcoxon signed-rank tests indicate no significant difference in the subscores across conditions (No-Identity treatment: Self- vs. Opp-condition: $p=0.400$; Identity treatment, same group identity: Self- vs. Opp-condition: $p=0.273$; for the Identity treatment with mixed group identity Selfvs. Opp-condition: $p=0.780$. Considering instead the data from the first period leads to the same conclusion. A regression analysis including all periods except the first one is reported in Table B.2 in the Appendix B.
} 


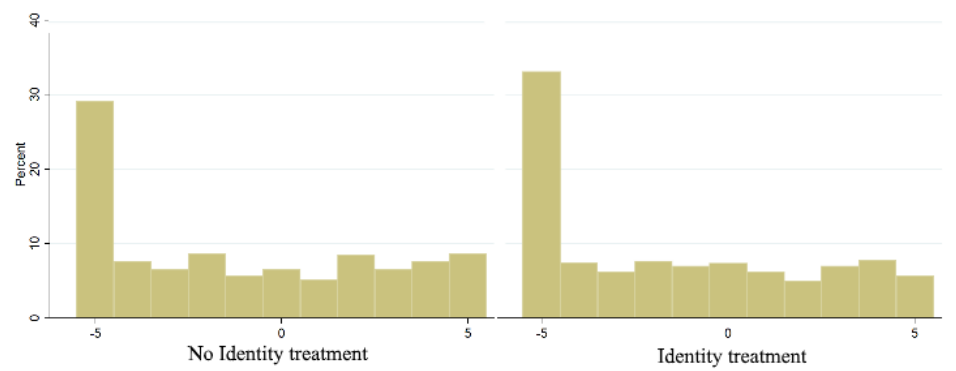

Figure 2b: Distribution of numbers reported in the Opp-condition, by treatment

In each condition, each number is expected to appear uniformly $9.09 \%$ of the time if reports are truthful. Figures $2 \mathrm{a}$ and $2 \mathrm{~b}$ suggest that the distribution of reported numbers is different from a uniform distribution in both conditions and treatments. ${ }^{13}$ The frequency of $5 \mathrm{~s}$ reported in the Self-condition was $27.73 \%$ in the No-Identity treatment and $36.52 \%$ in the Identity treatment; conversely, the frequency of -5 s reported in the Opp-condition was $29.10 \%$ and $33.01 \%$, respectively. ${ }^{14}$ This provides evidence of self-interested misreporting. Our protocol allows us to identify misreports precisely. A (small) majority of subjects told selfish lies. 103 subjects out of 192 (53.65\%) misreported self-interestedly at least once during the 16 periods. Among these subjects, 77 misreported at least once in each of the two conditions (40.10\%), 12 subjects misreported only in the Self-condition $(6.25 \%)$, and 14 subjects only in the Opp-condition (7.29\%).

Table 1 displays the absolute and relative frequencies of misreports, their average absolute intensity, and the absolute and relative frequencies of full misreports, by treatment and condition. ${ }^{15}$ Absolute intensity is defined as the difference between the reported random number and the actual number. Full misreport is equal to 1 if the subject lied and reported the highest possible number for himself or the lowest possible number for his

\footnotetext{
${ }^{13}$ For the following non-parametric tests, we consider only the first of the 16 periods. Each subject is taken as one independent observation. Each subject was taken as one independent observation. Tests were two-sided. $\chi^{2}$ goodness-of-fit tests rejected the uniform distribution in the Identity treatment $(p<$ $0.001)$, but not in the No-Identity treatment $(p=0.172)$. To increase the number of observations for these tests we multiply the reported numbers by -1 in the Opp-condition allowing us to merge the data from the two conditions. A similar strategy is used for the binomial tests reported in the footnote 14 .

${ }^{14}$ Binomial tests on the first period indicate that in the Identity treatment these numbers are significantly different from $9.09 \%(p<0.001)$. Conversely, in the No-Identity treatment these numbers do not reach standard levels of significance $(p=0.079)$.

${ }^{15}$ In Table 1 and the following tables and tests about selfish lies, we exclude the cases in which subjects could not misreport selfishly (their number was equal to 5 in the Self-condition and their opponent's number was equal to -5 in the Opp-condition).
} 
opponent, and 0 otherwise. This Table includes only selfish misreports (those increasing the subject's probability of winning). Table B.3 in Appendix B displays the same information on the cases where a subject underreported his own number or overreported his opponent's number.

Table 1: Performance, frequency and intensity of selfish misreporting, by treatment and condition

\begin{tabular}{|c|c|c|c|c|c|c|c|}
\hline Treatment & Condition & & $\begin{array}{l}\text { Average } \\
\text { subscore }\end{array}$ & $\begin{array}{l}\text { Relative } \\
\text { frequency } \\
\text { of } \\
\text { misreports }\end{array}$ & $\begin{array}{l}\text { Relative } \\
\text { frequency } \\
\text { of full } \\
\text { misreports }\end{array}$ & $\begin{array}{c}\text { Average } \\
\text { absolute } \\
\text { intensity of } \\
\text { misreports }\end{array}$ & $\mathrm{N}$ \\
\hline \multirow{2}{*}{ No-Identity } & Self & All & $6.93(0.07)$ & $27.52 \%$ & $83.97 \%$ & $5.32(0.25)$ & 512 \\
\hline & Opp & All & $6.82(0.08)$ & $27.40 \%$ & $85.00 \%$ & $4.92(0.26)$ & 512 \\
\hline \multirow{6}{*}{ Identity } & \multirow{3}{*}{ Self } & All & $6.64(0.06)$ & $32.46 \%$ & $90.88 \%$ & $5.29(0.17)$ & 1024 \\
\hline & & In-Group opponent & $6.40(0.09)$ & $30.57 \%$ & $90.71 \%$ & $5.21(0.24)$ & 512 \\
\hline & & Out-Group opponent & $6.89(0.07)$ & $34.36 \%$ & $91.02 \%$ & $5.36(0.24)$ & 512 \\
\hline & \multirow{3}{*}{ Opp } & All & $6.77(0.05)$ & $31.39 \%$ & $87.02 \%$ & $5.45(0.17)$ & 1024 \\
\hline & & In-Group opponent & $6.73(0.08)$ & $31.42 \%$ & $86.62 \%$ & $5.86(0.23)$ & 512 \\
\hline & & Out-Group opponent & $6.82(0.07)$ & $31.36 \%$ & $87.41 \%$ & $5.05(0.25)$ & 512 \\
\hline
\end{tabular}

Notes: Standard deviations are in parentheses. The average subscore is the average performance in each period of the decoding task. The relative frequency of misreports excludes the observations in which the subject's own random number is 5 in the Self-condition and those in which the opponent's random number is -5 in the Oppcondition. Full misreports correspond to the cases in which a subject misreports the highest possible number for himself $(+5)$ or the lowest possible number for his opponent $(-5)$. $\mathrm{N}$ is the total number of observations.

Table 1 shows that in the No-Identity treatment $27 \%$ of the subjects reported a higher number for themselves $(131 / 475)$ and the same percentage reported a lower number for their opponent $(120 / 438)$ when they had an opportunity to lie. In the Identity treatment, $32 \%(296 / 912)$ and $31 \%$ (285/908) of the subjects misreported in the Self- and in the Opp-condition, respectively. Subjects who lied selfishly misreported to the full-extent in the vast majority of cases (from $84 \%$ to $91 \%$ of the observations, depending on the treatment and condition). his is consistent with Kajackaite and Gneezy (2017): since the experimenter is able to observe misreporting (ex post facto), those with a higher moral cost of lying may misreport to a lesser extent than if there were no scrutiny at all, but those who are willing to misreport have no reluctance to lie in full.

Table B.3 in Appendix B shows that non-self-interested misreports were very rare. In 11 cases (emanating from 10 different subjects and representing $0.79 \%$ of the relevant 
observations) subjects underreported their own number; in 53 cases (emanating from 33 different subjects and representing $3.81 \%$ of the cases), they overreported their opponent's number. These cases are either errors or altruistic white lies motivated by the willingness to increase the opponent's chance to succeed. We favor the first interpretation because most subjects made these types of reports only once or twice. ${ }^{16}$ The rest of our analysis is based only on self-interested misreporting.

To compare selfish misreporting behavior across conditions, we first report two-sided Wilcoxon signed-rank tests based on averages at the session level. These tests show no significant difference between the decisions to misreport in the Self- and the Oppconditions in the No-Identity treatment $(\mathrm{N}=8, p=0.715)$ and in the Identity treatment $(\mathrm{N}=16, p=0.779)$. The differences are not significant either if we consider the absolute intensity of misreporting ( $p=0.715$ and $p=0.780$, respectively). We report next a regression analysis that investigates the determinants of misreporting, considering first the decision to misreport, and second the relative intensity of misreporting. The results are shown in Tables 2 and 3. Table 2 displays the marginal effects of seven random-effects logit models in which the dependent variable is the decision to misreport, with robust standard errors. These models vary the conditions and treatments included. Models (1) to (3) pool the decisions made in the two conditions. Models (4) and (5) consider the decisions made in the Self-condition and models (6) and (7) those made in the Opp-condition. Models (2), (4), and (6) include only the No-Identity treatment, and models (3), (5), and (7) only the Identity treatment. In model (1), the independent variables include dummy variables for the Identity treatment and for the Opp-condition, taking the Self-condition and the No-Identity treatment as the reference categories. Since the decision to misreport may be affected by the relative performance at the task, they also include the subject's subscore, the difference between subscores when the subject outperforms his opponent $\left(\max \left\{0\right.\right.$, subscore $_{i, t}-$ subscore $\left.\left._{j, t}\right\}\right)$, the difference between subscores when the subject is outperformed by his opponent $\left(\max \left\{0\right.\right.$, subscore $_{j, t}-$ subscore $\left.\left._{i, t}\right\}\right)$, and a dummy in case of a tie in performance. Since the decision to misreport may also be affected by relative luck,

\footnotetext{
${ }^{16}$ One subject overreported the opponent's number in seven out of eight cases and underreported his own number in two out of eight cases. But he also overreported his own number in four cases. His comments left in the post-experimental questionnaire suggest that the subject was confused.
} 
the independent variables include the subject's random number, the difference between the subject's and his opponent's numbers when the subject is luckier than his opponent $\left(\max \left\{0\right.\right.$, number $_{i, t}-$ number $\left.\left._{j, t}\right\}\right)$, the difference between numbers when the subject is less lucky than his opponent $\left(\max \left\{0\right.\right.$, number $_{j, t}-$ number $\left.\left._{i, t}\right\}\right)$, and a dummy in case of a tie. To control for a possible non-linear evolution of behavior over time, we added a time trend and its squared value. We included the subject's gender and the SVO angle (a higher angle indicates that the subject is more pro-social in the SVO test). The other characteristics include the subject's age and his number of past participations in a laboratory experiment. Finally, session fixed effects control for unobserved heterogeneity across sessions. The other models include the same independent variables, except the condition and treatment variables. In addition, models (3), (5), and (7) include a dummy variable ("In-group opponent") equal to 1 if the pair members share the same group identity and 0 otherwise.

Table 3 reports the marginal effects from seven random-effects Tobit regressions on the relative intensity of selfish misreporting. The dependent variable is the ratio between the actual and the maximum possible intensity of misreporting. ${ }^{17}$ We use Tobit models since data are censored on the right when subjects misreport to the full extent (i.e., subjects could not cheat more). ${ }^{18}$ These models have the same other characteristics as those reported in Table 2.

Contrary to Conjecture 1b, models (1) to (3) in Table 2 show that the probability of misreporting does not differ significantly between the Self- and the Opp-conditions in any treatment. ${ }^{19}$ Table 3 indicates that the relative intensity of misreporting is higher in

\footnotetext{
${ }^{17}$ For example, if a participant gets a random number of 2 and reports a 4 the ratio is equal to 0.66 ; if he reports a 5 , the ratio is equal to 1 . The dependent variable is equal to 1 if a participant misreported a 5 in the Self-condition or a -5 in the Opp-condition. It is equal to 0 if the subject did not misreport. Note that non-parametric tests based on the average relative intensity of misreporting at the session level give the same results than the tests based on the absolute intensity of misreporting.

${ }^{18} \mathrm{We}$ do not include in these regressions the cases of non-selfish misreporting as they are probably mostly mistakes. Note that if we include them, the results of Table 3 remain qualitatively similar.

${ }^{19} \mathrm{To}$ assess the significance of this null result we calculated the achieved power of our design for three levels of size effect. We use a simulation-based approach on model (1) in Table 2 using STATA with a p-value sets at $5 \%$. Our achieved power is $30 \%, 82 \%$ and $99 \%$ for a low, medium and large effect size (Cohen's $d$ is equal to $0.3,0.6$ and 0.9 , respectively).
} 
the Self than in the Opp-condition. However, the effect is small and only significant in the Identity treatment.

The two tables also indicate that the determinants of behavior differ across conditions, suggesting that subjects did not focus exactly on the same information. In the Selfcondition, the likelihood of misreporting (only in the No-Identity treatment) and the relative intensity of misreporting react mainly to bad luck in terms of one's random number (models (6)). In contrast, in the Opp-condition the value of these coefficients increases when the performance of the subject increases. Additionally, the relative intensity of misreporting is significantly higher the more the opponent is ahead in terms of random number in both treatments (models (4) and (5)). The probability to misreport the opponent's number is also significantly higher the more the opponent is ahead either in terms of performance (in the No-Identity treatment) or in terms of luck. Moreover, subjects are significantly more likely to misreport their opponent's number over time, whereas no clear time pattern can be discerned in the Self-condition, possibly because people have originally more scruples sabotaging others. The increase in the relative intensity of misreporting over time observed in the Opp-condition is consistent with the escalation of self-serving dishonesty reported by Garrett et al. (2016).

Finally, selfishness, as measured by a lower SVO angle in the SVO test, and being a male tend to increase the likelihood and the relative intensity of misreporting, which is consistent with the previous literature (e.g., Dreber and Johannesson, 2008; Nieken and Dato, 2016; Muehlheusser et al., 2015, on gender; and Grosch and Rau, 2017, on pro-sociality and gender). However, the effect of gender varies across treatments and conditions.

\subsection{Group Identity and Misreporting Behavior}

We next present our main finding regarding the impact of group identity:

Result 2: Group identity has no significant impact on the willingness to misreport and on the relative intensity of misreporting, regardless of the condition.

This rejects Conjecture 2a. 
Table 2: Determinants of the decision to make a selfish misreport

\begin{tabular}{|c|c|c|c|c|c|c|c|}
\hline $\begin{array}{l}\text { Dependent variable: } \\
\text { Selfish misreport }\end{array}$ & \multicolumn{3}{|c|}{ All conditions } & \multicolumn{2}{|c|}{ Opp-condition } & \multicolumn{2}{|c|}{ Self-condition } \\
\hline Treatments & $\begin{array}{l}\text { All } \\
(1)\end{array}$ & $\begin{array}{c}\text { No-Identity } \\
(2)\end{array}$ & $\begin{array}{l}\text { Identity } \\
(3)\end{array}$ & $\begin{array}{c}\text { No-Identity } \\
\text { (4) }\end{array}$ & $\begin{array}{c}\text { Identity } \\
(5)\end{array}$ & $\begin{array}{c}\text { No-Identity } \\
(6)\end{array}$ & $\begin{array}{l}\text { Identity } \\
(7)\end{array}$ \\
\hline Identity treatment & $\begin{array}{l}-0.042 \\
(0.128)\end{array}$ & - & - & - & - & - & - \\
\hline Opp-condition & $\begin{array}{l}-0.017 \\
(0.014)\end{array}$ & $\begin{array}{c}0.007 \\
(0.027)\end{array}$ & $\begin{array}{l}-0.023 \\
(0.016)\end{array}$ & - & - & - & - \\
\hline In-group opponent & - & - & $\begin{array}{l}-0.023 \\
(0.022)\end{array}$ & - & $\begin{array}{l}-0.027 \\
(0.017)\end{array}$ & - & $\begin{array}{l}-0.039 \\
(0.087)\end{array}$ \\
\hline Subscore $_{i, t}$ & $\begin{array}{c}0.017^{* *} \\
(0.008)\end{array}$ & $\begin{array}{l}0.026^{*} \\
(0.015)\end{array}$ & $\begin{array}{c}0.004 \\
(0.011)\end{array}$ & $\begin{array}{c}0.043^{* *} \\
(0.020)\end{array}$ & $\begin{array}{c}0.011 \\
(0.008)\end{array}$ & $\begin{array}{c}0.030 \\
(0.021)\end{array}$ & $\begin{array}{c}0.012 \\
(0.048)\end{array}$ \\
\hline Tie: subscore $_{i, t}=$ subscore $_{j, t}$ & $\begin{array}{c}0.026 \\
(0.021)\end{array}$ & $\begin{array}{l}-0.028 \\
(0.037)\end{array}$ & $\begin{array}{l}0.058^{*} \\
(0.032)\end{array}$ & $\begin{array}{l}-0.065 \\
(0.049)\end{array}$ & $\begin{array}{l}0.056^{* *} \\
(0.027)\end{array}$ & $\begin{array}{l}0.008 \\
(0.055)\end{array}$ & $\begin{array}{c}0.047 \\
(0.120)\end{array}$ \\
\hline $\operatorname{Max}\left\{0\right.$, subscore $_{i, t}-$ subscore $\left._{j, t}\right\}$ & $\begin{array}{l}-0.005 \\
(0.008)\end{array}$ & $\begin{array}{l}-0.002 \\
(0.015)\end{array}$ & $\begin{array}{l}-0.007 \\
(0.011)\end{array}$ & $\begin{array}{l}-0.016 \\
(0.018)\end{array}$ & $\begin{array}{l}-0.005 \\
(0.008)\end{array}$ & $\begin{array}{l}<-0.001 \\
(0.020)\end{array}$ & $\begin{array}{l}-0.003 \\
(0.017)\end{array}$ \\
\hline $\operatorname{Max}\left\{0\right.$, subscore $_{j, t}-$ subscore $\left._{i, t}\right\}$ & $\begin{array}{c}0.024^{* * *} \\
(0.008)\end{array}$ & $\begin{array}{c}0.040^{* *} \\
(0.016)\end{array}$ & $\begin{array}{c}0.010 \\
(0.013)\end{array}$ & $\begin{array}{c}0.036^{* *} \\
(0.018)\end{array}$ & $\begin{array}{l}0.018^{*} \\
(0.010)\end{array}$ & $\begin{array}{c}0.045 \\
(0.028)\end{array}$ & $\begin{array}{l}0.015 \\
(0.046)\end{array}$ \\
\hline Random number ${ }_{i, t}$ & $\begin{array}{l}<0.001 \\
(0.003)\end{array}$ & $\begin{array}{l}-0.005 \\
(0.006)\end{array}$ & $\begin{array}{l}0.011^{*} \\
(0.006)\end{array}$ & $\begin{array}{l}0.017^{*} \\
(0.010)\end{array}$ & $\begin{array}{c}0.004 \\
(0.003)\end{array}$ & $\begin{array}{c}-0.040^{* * *} \\
(0.010)\end{array}$ & $\begin{array}{l}-0.004 \\
(0.007)\end{array}$ \\
\hline Tie: number $_{i, t}=$ number $_{j, t}$ & $\begin{array}{l}-0.004 \\
(0.025)\end{array}$ & $\begin{array}{c}0.002 \\
(0.056)\end{array}$ & $\begin{array}{c}0.024 \\
(0.032)\end{array}$ & $\begin{array}{l}-0.007 \\
(0.088)\end{array}$ & $\begin{array}{l}-0.004 \\
(0.023)\end{array}$ & $\begin{array}{c}0.081 \\
(0.063)\end{array}$ & $\begin{array}{l}-0.012 \\
(0.086)\end{array}$ \\
\hline $\operatorname{Max}\left\{0\right.$, number $_{i, t}-$ number $\left._{j, t}\right\}$ & $\begin{array}{c}-0.011^{* *} \\
(0.005)\end{array}$ & $\begin{array}{l}-0.004 \\
(0.010)\end{array}$ & $\begin{array}{c}-0.019^{* *} \\
(0.008)\end{array}$ & $\begin{array}{l}-0.006 \\
(0.013)\end{array}$ & $\begin{array}{c}-0.013^{* *} \\
(0.005)\end{array}$ & $\begin{array}{c}0.011 \\
(0.014)\end{array}$ & $\begin{array}{l}-0.004 \\
(0.020)\end{array}$ \\
\hline $\operatorname{Max}\left\{0\right.$, number $_{j, t}-$ number $\left._{i, t}\right\}$ & $\begin{array}{c}0.010^{* * *} \\
(0.003)\end{array}$ & $\begin{array}{l}0.011^{*} \\
(0.006)\end{array}$ & $\begin{array}{c}0.017^{* *} \\
(0.008)\end{array}$ & $\begin{array}{c}0.025^{* * *} \\
(0.008)\end{array}$ & $\begin{array}{c}0.009^{* *} \\
(0.004)\end{array}$ & $\begin{array}{l}-0.001 \\
(0.009)\end{array}$ & $\begin{array}{c}0.002 \\
(0.005)\end{array}$ \\
\hline Period & $\begin{array}{c}0.025^{* * *} \\
(0.008)\end{array}$ & $\begin{array}{c}0.039 * * \\
(0.017)\end{array}$ & $\begin{array}{c}0.023^{* *} \\
(0.011)\end{array}$ & $\begin{array}{l}0.042^{*} \\
(0.024)\end{array}$ & $\begin{array}{c}0.019^{* *} \\
(0.009)\end{array}$ & $\begin{array}{c}0.020 \\
(0.020)\end{array}$ & $\begin{array}{c}0.014 \\
(0.011)\end{array}$ \\
\hline Period squared & $\begin{array}{c}-0.001^{* *} \\
(0.000)\end{array}$ & $\begin{array}{c}-0.002^{* *} \\
(0.001)\end{array}$ & $\begin{array}{l}-0.001 \\
(0.001)\end{array}$ & $\begin{array}{c}-0.002 \\
(0.001)\end{array}$ & $\begin{array}{c}-0.001 \\
(0.001)\end{array}$ & $\begin{array}{c}-0.001 \\
(0.001)\end{array}$ & $\begin{array}{l}<-0.001 \\
(0.001)\end{array}$ \\
\hline SVO angle & $\begin{array}{c}-0.006^{* * *} \\
(0.002)\end{array}$ & $\begin{array}{c}-0.008^{* * *} \\
(0.003)\end{array}$ & $\begin{array}{c}-0.005^{* *} \\
(0.003)\end{array}$ & $\begin{array}{c}-0.007^{* *} \\
(0.003)\end{array}$ & $\begin{array}{c}-0.005^{* *} \\
(0.002)\end{array}$ & $\begin{array}{l}-0.007^{*} \\
(0.004)\end{array}$ & $\begin{array}{l}-0.007 \\
(0.031)\end{array}$ \\
\hline Male & $\begin{array}{c}0.165^{* * *} \\
(0.054)\end{array}$ & $\begin{array}{c}0.191^{* *} \\
(0.087)\end{array}$ & $\begin{array}{c}0.151 \\
(0.134)\end{array}$ & $\begin{array}{c}0.177^{* *} \\
(0.087)\end{array}$ & $\begin{array}{c}0.146 \\
(0.093)\end{array}$ & $\begin{array}{c}0.151 \\
(0.108)\end{array}$ & $\begin{array}{c}0.161 \\
(0.235)\end{array}$ \\
\hline Other individual characteristics & Yes & Yes & Yes & Yes & Yes & Yes & Yes \\
\hline Session fixed effects & Yes & Yes & Yes & Yes & Yes & Yes & Yes \\
\hline [1pt] Number of observations & 2734 & 914 & 1820 & 438 & 908 & 476 & 912 \\
\hline Number of clusters & 192 & 64 & 128 & 64 & 128 & 64 & 128 \\
\hline Pseudo-loglikelihood & -690.760 & -278.859 & -232.498 & -147.249 & -399.179 & -156.057 & -223.060 \\
\hline Wald Chi2 & 123.544 & 54.300 & 91.508 & 49.371 & 135.267 & 38.682 & 64.569 \\
\hline $\mathrm{p}>$ chi2 & $<0.001$ & $<0.001$ & $<0.001$ & $<0.001$ & $<0.001$ & 0.002 & $<0.001$ \\
\hline
\end{tabular}

Notes: This Table reports marginal effects from random-effects logit regressions with robust standard errors clustered at the subject level in parentheses. The regressions exclude the observations in which the subject's own random number is 5 in the Self-condition and those in which the opponent's random number is -5 in the Opp-condition. ${ }^{* * *}$ indicate significance at the $1 \%$ level, ${ }^{* *}$ at the $5 \%$ level, and $*$ at the $10 \%$ level. 
Table 3: Determinants of the relative intensity of selfish misreporting

\begin{tabular}{|c|c|c|c|c|c|c|c|}
\hline $\begin{array}{l}\text { Dependent variable: } \\
\text { Relative intensity of selfish } \\
\text { misreporting }\end{array}$ & \multicolumn{3}{|c|}{ All conditions } & \multicolumn{2}{|c|}{ Opp-condition } & \multicolumn{2}{|c|}{ Self-condition } \\
\hline Treatments & $\begin{array}{l}\text { All } \\
(1)\end{array}$ & $\begin{array}{c}\text { No-Identity } \\
(2)\end{array}$ & $\begin{array}{c}\text { Identity } \\
(3)\end{array}$ & $\begin{array}{l}\text { No-Identity } \\
(4)\end{array}$ & $\begin{array}{c}\text { Identity } \\
(5)\end{array}$ & $\begin{array}{l}\text { No-Identity } \\
(6)\end{array}$ & $\begin{array}{c}\text { Identity } \\
(7)\end{array}$ \\
\hline Identity treatment & $\begin{array}{l}-0.019 \\
(0.041)\end{array}$ & - & - & - & - & - & - \\
\hline Opp-condition & $\begin{array}{c}-0.006^{* *} \\
(0.003)\end{array}$ & $\begin{array}{c}0.003 \\
(0.005)\end{array}$ & $\begin{array}{c}-0.009^{* * *} \\
(0.003)\end{array}$ & - & - & - & - \\
\hline In-group opponent & - & - & $\begin{array}{l}-0.004 \\
(0.003)\end{array}$ & - & $\begin{array}{l}-0.003 \\
(0.004)\end{array}$ & - & $\begin{array}{c}-0.007^{*} \\
(0.004)\end{array}$ \\
\hline Subscore $_{i, t}$ & $\begin{array}{c}0.005^{* * *} \\
(0.001)\end{array}$ & $\begin{array}{c}0.007^{* *} \\
(0.003)\end{array}$ & $\begin{array}{c}0.004^{* *} \\
(0.002)\end{array}$ & $\begin{array}{c}0.010^{* *} \\
(0.004)\end{array}$ & $\begin{array}{c}0.005 * * \\
(0.002)\end{array}$ & $\begin{array}{c}0.009 * * \\
(0.005)\end{array}$ & $\begin{array}{c}0.002 \\
(0.002)\end{array}$ \\
\hline Tie: subscore $_{i, t}=$ subscore $_{j, t}$ & $\begin{array}{l}0.008^{*} \\
(0.004)\end{array}$ & $\begin{array}{l}-0.004 \\
(0.008)\end{array}$ & $\begin{array}{c}0.014^{* * * *} \\
(0.005)\end{array}$ & $\begin{array}{l}-0.001 \\
(0.013)\end{array}$ & $\begin{array}{c}0.011 \\
(0.007)\end{array}$ & $\begin{array}{l}-0.005 \\
(0.012)\end{array}$ & $\begin{array}{c}0.013^{* *} \\
(0.007)\end{array}$ \\
\hline $\operatorname{Max}\left\{0\right.$, subscore $_{i, t}-$ subscore $\left._{j, t}\right\}$ & $\begin{array}{c}-0.003^{*} \\
(0.001)\end{array}$ & $\begin{array}{l}-0.003 \\
(0.003)\end{array}$ & $\begin{array}{l}-0.003 \\
(0.002)\end{array}$ & $\begin{array}{l}-0.004 \\
(0.004)\end{array}$ & $\begin{array}{l}-0.004 \\
(0.003)\end{array}$ & $\begin{array}{l}-0.003 \\
(0.005)\end{array}$ & $\begin{array}{l}-0.002 \\
(0.002)\end{array}$ \\
\hline $\operatorname{Max}\left\{0\right.$, subscore $_{j, t}-$ subscore $\left._{i, t}\right\}$ & $\begin{array}{c}0.006^{* * *} \\
(0.002)\end{array}$ & $\begin{array}{c}0.008^{* *} \\
(0.003)\end{array}$ & $\begin{array}{c}0.005^{* * * *} \\
(0.002)\end{array}$ & $\begin{array}{l}0.010^{*} \\
(0.005)\end{array}$ & $\begin{array}{l}0.005^{*} \\
(0.003)\end{array}$ & $\begin{array}{c}0.008 \\
(0.005)\end{array}$ & $\begin{array}{c}0.003 \\
(0.003)\end{array}$ \\
\hline Random number $_{i, t}$ & $\begin{array}{l}-0.000 \\
(0.001)\end{array}$ & $\begin{array}{l}-0.001 \\
(0.001)\end{array}$ & $\begin{array}{c}0.000 \\
(0.001)\end{array}$ & $\begin{array}{c}0.001 \\
(0.002)\end{array}$ & $\begin{array}{c}0.001 \\
(0.001)\end{array}$ & $\begin{array}{c}-0.005^{* *} \\
(0.002)\end{array}$ & $\begin{array}{l}-0.000 \\
(0.001)\end{array}$ \\
\hline Tie: number $_{i, t}=$ number $_{j, t}$ & $\begin{array}{c}0.006 \\
(0.005)\end{array}$ & $\begin{array}{c}0.013 \\
(0.011)\end{array}$ & $\begin{array}{c}0.002 \\
(0.006)\end{array}$ & $\begin{array}{c}0.018 \\
(0.016)\end{array}$ & $\begin{array}{c}0.011 \\
(0.009)\end{array}$ & $\begin{array}{c}0.020 \\
(0.016)\end{array}$ & $\begin{array}{l}-0.002 \\
(0.008)\end{array}$ \\
\hline $\operatorname{Max}\left\{0\right.$, number $_{i, t}-$ number $\left._{j, t}\right\}$ & $\begin{array}{l}-0.000 \\
(0.001)\end{array}$ & $\begin{array}{c}0.001 \\
(0.002)\end{array}$ & $\begin{array}{l}-0.001 \\
(0.001)\end{array}$ & $\begin{array}{c}0.001 \\
(0.002)\end{array}$ & $\begin{array}{l}-0.002 \\
(0.001)\end{array}$ & $\begin{array}{c}0.003 \\
(0.002)\end{array}$ & $\begin{array}{l}-0.000 \\
(0.001)\end{array}$ \\
\hline $\operatorname{Max}\left\{0\right.$, number $_{j, t}-$ number $\left._{i, t}\right\}$ & $\begin{array}{c}0.003^{* * *} \\
(0.001)\end{array}$ & $\begin{array}{c}0.003 * * \\
(0.001)\end{array}$ & $\begin{array}{c}0.002^{* * * *} \\
(0.001)\end{array}$ & $\begin{array}{c}0.006^{* * *} \\
(0.002)\end{array}$ & $\begin{array}{c}0.004^{* * *} \\
(0.001)\end{array}$ & $\begin{array}{c}0.002 \\
(0.002)\end{array}$ & $\begin{array}{c}0.001 \\
(0.001)\end{array}$ \\
\hline Period & $\begin{array}{c}0.004^{* * *} \\
(0.001)\end{array}$ & $\begin{array}{c}0.006^{* *} \\
(0.003)\end{array}$ & $\begin{array}{c}0.003^{* *} \\
(0.002)\end{array}$ & $\begin{array}{c}0.011^{* *} \\
(0.004)\end{array}$ & $\begin{array}{c}0.006 * * \\
(0.002)\end{array}$ & $\begin{array}{c}0.001 \\
(0.004)\end{array}$ & $\begin{array}{c}0.001 \\
(0.002)\end{array}$ \\
\hline Period squared & $\begin{array}{l}-0.000 \\
(0.000)\end{array}$ & $\begin{array}{c}-0.000^{*} \\
(0.000)\end{array}$ & $\begin{array}{l}-0.000 \\
(0.000)\end{array}$ & $\begin{array}{c}-0.001^{* *} \\
(0.000)\end{array}$ & $\begin{array}{c}-0.000 \\
(0.000)\end{array}$ & $\begin{array}{c}0.000 \\
(0.000)\end{array}$ & $\begin{array}{c}0.000 \\
(0.000)\end{array}$ \\
\hline SVO angle & $\begin{array}{c}-0.002^{* * *} \\
(0.001)\end{array}$ & $\begin{array}{c}-0.002^{*} \\
(0.001)\end{array}$ & $\begin{array}{c}-0.002^{* *} \\
(0.001)\end{array}$ & $\begin{array}{c}-0.002^{*} \\
(0.001)\end{array}$ & $\begin{array}{c}-0.002^{*} \\
(0.001)\end{array}$ & $\begin{array}{l}-0.002 \\
(0.001)\end{array}$ & $\begin{array}{c}-0.002^{* *} \\
(0.001)\end{array}$ \\
\hline Male & $\begin{array}{c}0.043^{* *} \\
(0.018)\end{array}$ & $\begin{array}{c}0.039 \\
(0.030)\end{array}$ & $\begin{array}{c}0.047^{* *} \\
(0.022)\end{array}$ & $\begin{array}{c}0.041 \\
(0.032)\end{array}$ & $\begin{array}{l}0.045^{*} \\
(0.023)\end{array}$ & $\begin{array}{c}0.036 \\
(0.031)\end{array}$ & $\begin{array}{c}0.048^{* *} \\
(0.022)\end{array}$ \\
\hline $\begin{array}{l}\text { Other individual characteristics } \\
\text { Session fixed effects }\end{array}$ & $\begin{array}{l}\text { Yes } \\
Y e s\end{array}$ & $\begin{array}{l}Y e s \\
Y e s\end{array}$ & $\begin{array}{l}\text { Yes } \\
\text { Yes }\end{array}$ & $\begin{array}{l}\text { Yes } \\
\text { Yes }\end{array}$ & $\begin{array}{l}Y e s \\
Y e s\end{array}$ & $\begin{array}{l}\text { Yes } \\
Y e s\end{array}$ & $\begin{array}{l}\text { Yes } \\
Y e s\end{array}$ \\
\hline Number of observations & 2734 & 914 & 1820 & 438 & 908 & 476 & 912 \\
\hline Number of right censored observat. & 729 & 212 & 517 & 102 & 248 & 110 & 269 \\
\hline Number of clusters & 192 & 64 & 128 & 64 & 128 & 64 & 128 \\
\hline Pseudo-loglikelihood & -937.044 & -371.219 & -546.565 & -204.396 & -317.826 & -222.372 & -341.095 \\
\hline Wald Chi2 & 233.733 & 89.845 & 164.208 & 66.988 & 110.332 & 51.543 & 79.043 \\
\hline $\mathrm{p}>$ chi 2 & $<0.001$ & $<0.001$ & $<0.001$ & $<0.001$ & $<0.001$ & $<0.001$ & $<0.001$ \\
\hline
\end{tabular}

Notes: This Table reports marginal effects from random-effects Tobit regressions with standard errors in parentheses. The dependent variable is the ratio between actual and maximum possible misreporting. The regressions exclude the observations in which the subject's own random number is 5 in the Self-condition and those in which the opponent's random number is -5 in the Opp-condition. *** indicate significance at the $1 \%$ level, ** at the $5 \%$ level, and $*$ at the $10 \%$ level. 


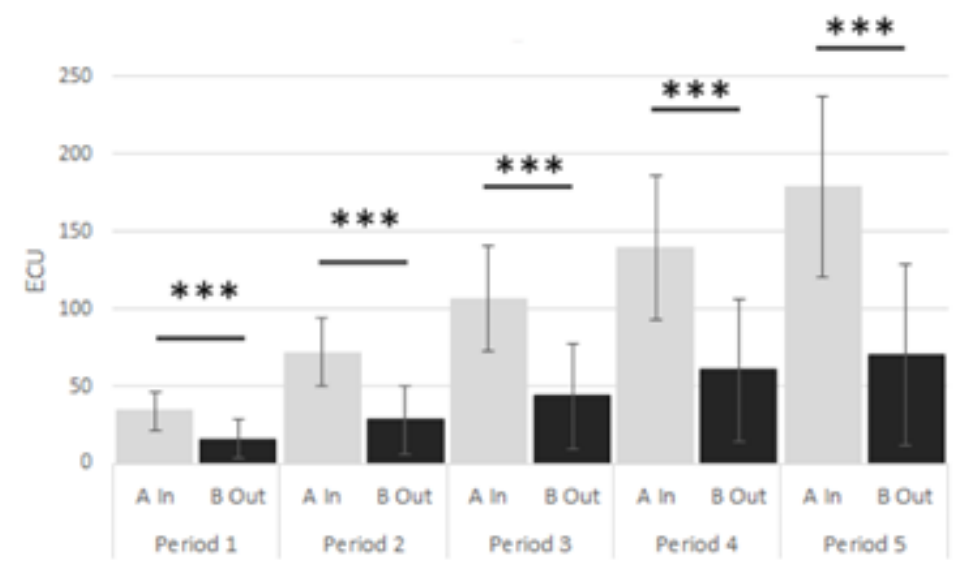

Figure 3: Average allocation in ECU as a third-party in scenario 3, by period (stage 3 of the group identity induction procedure)

Notes: "In" stands for in-group and "Out" for out-group. In scenario 3, person A is an in-group member and $\mathrm{B}$ is an out-group member. ${ }^{* * *}$ indicate significance at the $1 \%$ level in two-sided pair-wise t-tests.

Support for Result 2: First, to validate our group identity induction, we test whether subjects exhibit in-group favoritism in the other-other allocation task (scenario 3 ) in the third stage of the procedure. In this scenario, they had to decide as a third party how to share a certain amount of ECUs between person A (in their in-group) and person B (in their out-group). The amount to share increased by increments of 50 ECUs across periods. Figure 3 displays the average allocation of ECUs in each of the five periods.

In this task, subjects favored in-groups and discriminated against out-groups. When pooling all the data, we find that they allocated 2.68 times more to an in-group member (106.33 ECUs) than to an out-group member (39.67 ECUs) (two-sided pairwise t-test, $p<0.001)$. As seen in Figure 3, the difference is significant in each period. Importantly, in the two other scenarios the allocations differed significantly neither when both persons $\mathrm{A}$ and $\mathrm{B}$ were from the same group as the subject (scenario 1), and when both were from the other group (scenario 2) (see Figure C.2 in the Appendix C). This shows that the induction of group identity was successful.

Although subjects expressed in-group favoritism in this task, we found no significant difference in the decisions to misreport between the No-Identity and the Identity treatments, 
regardless of the condition. This is supported by the regressions reported in Tables 2 and $3 .^{20}$ In model (1), the Identity treatment variable is not significant. Comparing models (2) and (3), (4) and (5), or (6) and (7) shows similar patterns in the extent of misreporting in the Identity and the No-Identity treatments (Table 3), but less significant variables in the Identity treatment compared to the No-Identity treatment regarding the probability to misreport (Table 2). ${ }^{21}$ Moreover, two-sided Wilcoxon signed-rank tests based on averages at the session level show that there is no significant difference in misreporting between subjects matched with an in-group and those matched with an out-group $(\mathrm{N}=16$, $p=0.161)$. This is validated by models (3), (5), and (7) relative to the Identity treatment.

Overall, this analysis suggests that in such a competitive environment, a competitor is first seen as an opponent, and the social distance with him in terms of minimal group identity is not perceived as a relevant characteristic leading one to change one's norm of behavior.

\subsection{Beliefs}

We introduce our last result:

Result 3: Individuals believe that group identity affects others' misreporting behavior, although they are not themselves influenced by the group identity of their opponent.

This does not support Conjecture $2 \mathrm{~b}$.

Support for Result 3: We did not elicit the subjects' beliefs about their opponent's misreporting behavior in each period to avoid biasing their behavior. Instead, beliefs were elicited at the end of the session by asking subjects to guess how many people among 10 participants randomly selected in past sessions misreported in scenarios corresponding to the Self- and to the Opp-conditions, depending on whether the participant's subscore

\footnotetext{
${ }^{20}$ To assess the significance of this null result we calculated the achieve power of our design for three levels of size effect. We use a simulation-based approach on model (3) in Table 2 using STATA with a p-value sets at $5 \%$. Our achieve power is $21 \%, 56 \%$ and $88 \%$ considering a low, a medium and a large effect size (Cohen's d equals to $0.3,0.6$ and 0.9 , respectively).

${ }^{21}$ The fact that in Table 2 almost none of the independent variables are significant in the Identity treatment is not driven by significant effects of opposite signs between observations corresponding to in-group matching and observations corresponding to out-group matching that would cancel out. Reestimating models (3), (5), and (7) on the subsamples of pairs sharing the same group identity and pairs with different group identities shows qualitatively the same results as in the models pooling both types of matches.
} 
was above or below that of his opponent. Thus, subjects reported four beliefs in the No-Identity treatment and eight beliefs in the Identity treatment, since in the latter treatment we distinguished beliefs about pairs of in-groups and beliefs about pairs of out-groups. Note that at the end of the session, subjects were not informed whether their opponents lied or not during the contests.

Table 4 reports OLS regressions in which the dependent variable is the individual's reported belief in the different scenarios. Robust standard errors are clustered at the individual level. Model (1) pools the data from both treatments and includes a control for the Identity treatment, while models (2) to (4) consider only the No-Identity treatment and models (5) to (7) only the Identity treatment. To correlate beliefs with behavior in the contests, models (3) and (6) are restricted to the sub-sample of subjects who never misreported and models (4) and (7) to the sub-sample of subjects who misreported at least once. In all models, the independent variables include a dummy equal to 1 if the belief is about the Self-condition scenario ("Reporting for the Self scenario"), and 0 if it is about the Opp-condition scenario. "Higher subscore player" is equal to 1 if the belief is about the player with a higher subscore, and 0 otherwise. Finally, we control for the same individual characteristics as in the previous tables. In the models relative to the Identity treatment, the independent variables include also an "In-group pair" dummy equal to 1 if the belief is about two participants who shared the same group identity, and 0 otherwise.

Table 4 shows that subjects believe that people lied less when ahead of their opponent in terms of performance (models (1), (5), and (7)) and that they lied more about their own number than about their opponent's number (model (1)). This is mainly driven by subjects who themselves misreported in the Identity treatment (model (7)). Finally, and regardless of whether they lied in the game or not, subjects believe that fewer people misreported when paired with someone from the same group (models (5) to (7)).

Note that in the No-Identity treatment, none of these variables are significant, regardless of the actual behavior. In the Identity treatment, these beliefs are consistent with our conjectures but not with the subjects' actual behavior. Even if they believe that individ- 
uals are less likely to cheat against an in-group, they do not misreport less when they are themselves in this situation: neither preferences nor beliefs lead them to compete more fairly against an opponent.

Table 4: Determinants of beliefs on misreporting decisions in past sessions

\begin{tabular}{|c|c|c|c|c|c|c|c|}
\hline \multirow{2}{*}{$\begin{array}{l}\text { Dependent } \\
\text { variable: Belief } \\
\text { about the number } \\
\text { of players who } \\
\text { misreported }\end{array}$} & \multirow[b]{2}{*}{ All subjects } & \multicolumn{3}{|c|}{ No-Identity treatment } & \multicolumn{3}{|c|}{ Identity treatment } \\
\hline & & $\begin{array}{c}\text { All } \\
\text { subjects } \\
(2) \\
\end{array}$ & $\begin{array}{c}\text { Subjects } \\
\text { who never } \\
\text { misreported } \\
(3)\end{array}$ & $\begin{array}{c}\text { Subjects } \\
\text { who } \\
\text { misreported } \\
(4)\end{array}$ & $\begin{array}{c}\text { All } \\
\text { subjects } \\
(5) \\
\end{array}$ & $\begin{array}{c}\text { Subjects } \\
\text { who never } \\
\text { misreported } \\
(6)\end{array}$ & $\begin{array}{c}\text { Subjects } \\
\text { who } \\
\text { misreported } \\
(7) \\
\end{array}$ \\
\hline Identity treatment & $\begin{array}{l}-0.583 \\
(0.975)\end{array}$ & - & - & - & - & - & - \\
\hline $\begin{array}{l}\text { Reporting for Self } \\
\text { scenario }\end{array}$ & $\begin{array}{c}0.333^{* *} \\
(0.137)\end{array}$ & $\begin{array}{c}0.133 \\
(0.225)\end{array}$ & $\begin{array}{c}0.220 \\
(0.459)\end{array}$ & $\begin{array}{c}0.077 \\
(0.243)\end{array}$ & $\begin{array}{c}0.383^{* *} \\
(0.162)\end{array}$ & $\begin{array}{c}0.211 \\
(0.217)\end{array}$ & $\begin{array}{c}0.555^{* *} \\
(0.245)\end{array}$ \\
\hline $\begin{array}{l}\text { Higher subscore } \\
\text { player }\end{array}$ & $\begin{array}{c}-0.380^{* *} \\
(0.152)\end{array}$ & $\begin{array}{l}-0.352 \\
(0.364)\end{array}$ & $\begin{array}{c}0.100 \\
(0.701)\end{array}$ & $\begin{array}{l}-0.641 \\
(0.413)\end{array}$ & $\begin{array}{c}-0.387^{* *} \\
(0.168)\end{array}$ & $\begin{array}{c}0.211 \\
(0.243)\end{array}$ & $\begin{array}{c}-0.984^{* * *} \\
(0.213)\end{array}$ \\
\hline In-group pair & - & - & - & - & $-0.426 * * *$ & $-0.398^{* * *}$ & $-0.453^{* * *}$ \\
\hline SVO angle & $\begin{array}{c}-0.025^{*} \\
(0.014)\end{array}$ & $\begin{array}{l}-0.008 \\
(0.019)\end{array}$ & $\begin{array}{c}0.035 \\
(0.027)\end{array}$ & $\begin{array}{l}-0.012 \\
(0.023)\end{array}$ & $\begin{array}{c}-0.031^{*} \\
(0.017)\end{array}$ & $\begin{array}{c}(0.143) \\
0.011 \\
(0.025)\end{array}$ & $\begin{array}{c}(0.132) \\
-0.047^{* *} \\
(0.022)\end{array}$ \\
\hline Male & $\begin{array}{c}0.509 \\
(0.458)\end{array}$ & $\begin{array}{l}-0.585 \\
(0.669)\end{array}$ & $\begin{array}{l}-0.161 \\
(0.800)\end{array}$ & $\begin{array}{c}-1.532^{*} \\
(0.775)\end{array}$ & $\begin{array}{c}0.866 \\
(0.544)\end{array}$ & $\begin{array}{c}0.204 \\
(0.621)\end{array}$ & $\begin{array}{c}1.012 \\
(0.621)\end{array}$ \\
\hline Constant & $5.230 * * *$ & $\begin{array}{c}7.020^{* * * *} \\
(1.049)\end{array}$ & $\begin{array}{c}2.997^{* *} \\
(1.229)\end{array}$ & $\begin{array}{c}9.429^{* * *} \\
(1.169)\end{array}$ & $\begin{array}{c}4.085^{* * *} \\
(1.047)\end{array}$ & $\begin{array}{c}1.042 \\
(1.189)\end{array}$ & $\begin{array}{c}5.891^{* *} \\
(2.345)\end{array}$ \\
\hline $\begin{array}{l}\text { Other individual } \\
\text { characteristics }\end{array}$ & Yes & Yes & Yes & Yes & Yes & Yes & Yes \\
\hline Session fixed effects & Yes & Yes & Yes & Yes & Yes & Yes & Yes \\
\hline Nb of obs. & 1280 & 256 & 100 & 156 & 1024 & 512 & 512 \\
\hline $\mathrm{Nb}$ of subjects & 192 & 64 & 25 & 39 & 128 & 64 & 64 \\
\hline $\mathrm{R} 2$ & 0.054 & 0.050 & 0.117 & 0.183 & 0.076 & 0.115 & 0.204 \\
\hline$p>F$ & 0.066 & 0.300 & 0.021 & 0.002 & $<0.001$ & $<0.001$ & $<0.001$ \\
\hline
\end{tabular}

Notes: The Table reports OLS regressions with robust standard errors clustered at the individual level in parentheses. *** indicate significance at the $1 \%$ level, ${ }^{* *}$ at the $5 \%$ level, and ${ }^{*}$ at the $10 \%$ level.

\section{$5 \quad$ Robustness tests}

In our experiment the extent to which people lie to increase their chance of winning the competition is not affected by whether the opponent is an in-group or an out-group and they tend to lie to the same extent when they report about themselves or about their opponent. However, the fact that lying can be detected by the experimenter at the individual level may generate a selection bias: individuals who dare to cheat in this environment are probably those who have the least moral cost from misbehaving (Kajackaite and Gneezy, 2017) and perhaps also care less about group identity. In contrast, people 
who are more sensitive to the environment may be more willing to refrain from cheating when the experimenter can detect their lies, may care more about their opponent's identity, and if so may be less willing to misreport their opponent's number than their own. To test the robustness of our finding regarding the null impact of group identity and condition on cheating, we designed a novel Identity-No-Scrutiny treatment and an Identity-No-Info treatment used as a control.

\section{Design}

The Identity-No-Scrutiny treatment (involving 104 new subjects in 5 sessions) is similar to the initial Identity treatment except that we use a mind game in which a lie cannot be detected by the experimenter at the individual level. ${ }^{22}$ Precisely, in each condition, after performing the task and after being informed of his subscore and of both the subscore and the group identity of his opponent, the subject has to think in his mind about a letter between $\mathrm{A}$ and $\mathrm{K}$, inclusive. Then, the subject's screen displays a table that matches randomly each letter with a number between -5 to +5 . The subject is requested to report the number that corresponds to the letter he has selected in his mind before seeing the table. For example, if the subject thought about letter B, he has to report the second value in the set; if the random set is " $+2,-5,0,-1,+4,+1,-2,-4,+5,+3$, 3 ", then he has to report -5 . In both conditions misreporting is possible and undetectable.

However, this treatment introduces two changes compared to the Identity treatment. First, the experimenter is no longer able to detect a lie at the individual level, which may increase lying by subjects who have a higher moral cost of lying and who are more sensitive to the environment. Second, when deciding on whether lying or not, there is now uncertainty about the opponent's random number in the Self-condition and about one's own random number in the Opp-condition. This difference could be seen as unimportant, as the main uncertainty lies in the fact that one's opponent can lie about the actual random number. However, the results reported in Tables 2 and 3 show that subjects are sensitive to the difference between their own and their opponent's random numbers. Therefore,

\footnotetext{
${ }^{22}$ Mind games have been used to study lying behavior without scrutiny by the experimenter in dierolling tasks (Jiang, 2015; Shalvi and De Dreu, 2014; Barfort et al., 2015; Potters and Stoop, 2016; Kajackaite and Gneezy, 2017), and in coin toss tasks (Garbarino et al., 2018).
} 
we also conducted the Identity-No-Info treatment as a control treatment (involving 100 new subjects in 5 sessions). This treatment is similar to the Identity treatment except that when they have to report, subjects are not informed about the number of their opponent in the Self-condition and about their own number in the Opp-condition. Like in the Identity-No-Scrutiny treatment there is uncertainty about the difference between the two numbers, but the degree of scrutiny is the same as in the original Identity treatment.

A significant difference in reporting behavior depending on whether the subject is matched with an in-group or an out-group in the Identity-No-Scrutiny treatment would suggest that scrutiny turns on or off the effect of group identity on misreporting. A significant difference depending on whether the subject reports his own number or his opponent's number in the Identity-No-Info treatment would suggest that uncertainty about the difference between the two numbers turns on or off the effect of self vs. other reporting on cheating. Finally, the comparison between the reporting behavior in the Opp- and the Self-conditions in the Identity-No-Scrutiny and the Identity-No-Info treatments allows us to test whether scrutiny or uncertainty affects how subjects report for themselves vs. for their opponent.

\section{Results}

We find evidence of misreporting in both new treatments, although in the Identity-NoScrutiny treatment the evidence is only based on comparisons of the theoretical and empirical distributions of the reported numbers since we do not know the true values of the random draws. A visual inspection of the reported numbers' distributions in the new treatments (Figures C.3 and C.4 in the Appendix C) clearly shows that these distributions are not uniform, like in the initial treatments (Figures $2 \mathrm{a}$ and $2 \mathrm{~b}$ ). Non-parametric statistics on individual data can only be conducted on the first period since data are no longer independent in the following periods. Two-sided $\chi^{2}$ goodness-of-fit tests reject a uniform distribution of the reported numbers in the first period in both treatments $(p<0.001)$. Compared to the first period of the initial Identity treatment, there is no significant difference with the Identity-No-Info treatment (two-sided Wilcoxon rank-sum test, $p=0.272$ ) but there is a significant difference with the Identity-No-Scrutiny treat- 
ment $(p<0.001)$. Subjects report significantly higher (lower) numbers for themselves (for the opponent) when there is no possible scrutiny from the experimenter, which is in line with the literature (Gneezy et al., 2018). The proportion of extreme numbers (5 in the Self-condition and -5 in the Opp-condition) is also significantly different from the expected proportion if reports were honest in both treatments (two-sided binomial tests, $p<0.001){ }^{23}$

Table 5 reports the average reported random numbers across conditions in the new treatments. Two-sided Wilcoxon signed-rank tests based on averages at the session level ${ }^{24}$ reveal no significant difference in reporting when the opponent is an in-group or an outgroup in both the Identity-No-Scrutiny treatment $(\mathrm{N}=10, p=0.786)$ and the IdentityNo-Info treatment $(\mathrm{N}=10, p=0.225)$. This is not due to a failure in the induction of group identity, as subjects show a clear in-group bias in the other-other allocation task (they allocate more ECUs to an in-group than to an out-group in Scenario 3, $p<0.001$ for all endowments, two-sided pairwise t-tests). In contrast, we find a significant difference between the Self- and the Opp-conditions in the Identity-No-Scrutiny treatment $(\mathrm{N}=10$, $p=0.043)$, but not in the Identity-No-Info treatment $(\mathrm{N}=10, p=0.500) .{ }^{25}$ In Appendix B we report a regression analysis controlling for the subjects' socio-demographic characteristics. Table B.4 studies the probability to misreport selfishly in the Identity-No-Info treatment using Logit models, and Table B.5 studies the determinants of the reported number in the Identity-No-Info and the Identity-No-Scrutiny treatments, using Tobit models. These regressions confirm the results based on the non-parametric tests.

These results show that the experimenter's scrutiny does not turn on or off the effect of group identity on reporting: in no treatment individuals adjust their reports to the group identity of their opponent. Similarly, uncertainty about the difference between the

\footnotetext{
${ }^{23}$ To increase the number of observations for both the $\chi^{2}$ goodness-of-fit and the binomial tests, we multiply the reported numbers by -1 in the Opp-condition. This allows us to pool the data from the Self and Opp-conditions.

${ }^{24}$ Here also, for the tests the reported numbers in the Opp-condition are multiplied by -1 .

${ }^{25}$ To assess the significance of these results we calculated the achieved power of our design for three levels of size effect. We used the software $\mathrm{G}^{*}$ Power with a p-value sets at $5 \%$. Our achieved power is $13 \%, 38 \%$ and $69 \%$ considering low, medium and large effect sizes (Cohen's $d$ is equal to 0.3, 0.6 and 0.9 , respectively).
} 
Table 5: Average reported random number by treatment and condition

\begin{tabular}{|c|c|c|c|c|}
\hline Treatment & Condition & Opponent's identity & Average reported number & $\mathrm{N}$ \\
\hline \multirow{6}{*}{$\begin{array}{l}\text { Identity } \\
\text { No-Scrutiny }\end{array}$} & \multirow{3}{*}{ Self } & All & $1.52(0.06)$ & 800 \\
\hline & & In-group opponent & $1.53(0.09)$ & 400 \\
\hline & & Out-group opponent & $1.50(0.09)$ & 400 \\
\hline & \multirow{3}{*}{ Opp } & All & $-1.00(0.07)$ & 800 \\
\hline & & In-group opponent & $-1.01(0.09)$ & 400 \\
\hline & & Out-group opponent & $-0.99(0.09)$ & 400 \\
\hline \multirow{6}{*}{$\begin{array}{l}\text { Identity } \\
\text { No-Info }\end{array}$} & \multirow{3}{*}{ Self } & All & $0.91(0.06)$ & 832 \\
\hline & & In-group opponent & $0.85(0.09)$ & 416 \\
\hline & & Out-group opponent & $0.98(0.09)$ & 416 \\
\hline & \multirow{3}{*}{ Opp } & All & $-0.95(0.06)$ & 832 \\
\hline & & In-group opponent & $-0.95(0.09)$ & 416 \\
\hline & & Out-group opponent & $-0.95(0.09)$ & 416 \\
\hline
\end{tabular}

two numbers does not turn on or off the effect of self vs. other reporting, as individuals do not report differently their own numbers and their opponent's numbers either in the Identity-No-Info (see Table B.4 in the Appendix B) or in the initial Identity treatment (see Table 2). However, when the experimenter's scrutiny is removed, individuals report significantly higher absolute numbers in the Self-condition than in the Opp-condition (see Table B.5, in the Appendix B). An interpretation is that when the moral cost of misreporting is reduced, some individuals who would not lie under scrutiny are lying, especially to overreport their own number. This supports our last result:

Result 4: Even when the experimenter's scrutiny is removed, individuals do not adjust their behavior to the group identity of their opponent but in this setting they report higher absolute numbers for themselves than for their opponent.

\section{Discussion and Conclusion}

Studying ethics in competition, we explored whether social distance from an opponent in terms of group identity and the nature of reporting (about oneself or the opponent) affects the willingness to cheat to increase one's chance to succeed. First, we found that less than half of the subjects never misreport, and those who misreport do it to the 
full extent most of the time. This goes against the idea of a convex cost of lying (e.g., Mazar et al., 2008; Lundquist et al., 2009; Fischbacher and Föllmi-Heusi, 2013). Recent models (Dufwenberg and Dufwenberg, 2018; Gneezy et al., 2018; Khalmetski and Sliwka, 2017) have shown that individuals may refrain from reporting the highest outcome because this may alter their reputation vis-à-vis others or the experimenter. Behavior in our experiment is more consistent with the notion of a fixed cost of lying under scrutiny (e.g., Kajackaite and Gneezy, 2017). Individuals suffering a sufficiently high moral cost abstain from misreporting, whereas the others lie in full. Moreover, cheaters may be less reluctant to lie in full in our game since the report determines only a fraction of the final score which itself affects the probability of winning but not directly the actual outcome of the competition. This may weaken the feeling of responsibility.

A second finding is that cheaters underreport their opponent's outcome as much as they exaggerate their own outcome. This contrasts with Rigdon and D'Esterre (2015) who found that people lie less when reporting the performance of another subject than when reporting their own performance. However, our results become consistent with theirs when we remove the experimenter's scrutiny (as in their study), as in this condition subjects report higher numbers for themselves than for their opponent in absolute terms. This could be explained by the existence of conditional liars: individuals who are more sensitive to the moral cost of lying may be more likely to lie when there is no scrutiny and also more likely to misreport their own outcome than another person's outcome perhaps if the latter type of lie is perceived as aggressive.

Finally, the fact that group identity does not affect misreporting in any condition contrasts both with our expectation and those of the subjects that people would be more likely to lie at the detriment of an out-group. It also differs from (Banerjee et al., 2018) who found in the context of castes in India that the lying behavior of people from the dominant caste was discriminatory against previous competitors from the backward caste after they learned that they lost the competition. The difference may result from the fact that in our experiment, group identity was minimal and the opportunity to lie was embedded in the contest game, whereas it followed competition in their case. It also differs 
fromDella Valle and Ploner (2017) who found that dishonesty increases after being treated unfairly by a dictator from another group identity. The difference can be due to our competitive environment but not to the fact that lying can be detected at the individual level since in our treatment using a mind game group identity does not affect either reporting behavior. Note that our results are in line with those of Feldhaus and Mans (2014) who found no effect of social identity on lying in a sender-receiver game, and with those of Chowdhury et al. (2016) who found an effect of group identity on group conflict when group identity was natural but not when it was artificially induced as in our study.

In the context of distributive choices, Guala and Filippin (2017) proposed that group identity has no systematic effect across contexts because it is a heuristic rather than a social preference or a norm. Our interpretation is that in the context of repeated competition, the willingness to win is stronger than affiliation. A competitor, whether socially close or not, is above all an opponent to beat. This does not mean that ethics is indifferent to the composition of teams but the impact of group identity on unethical behavior may be more sensitive to the environment than previously considered. It would thus be important to investigate in which environments group identity is more, or less, likely to influence unethical practices. For example, we know that misreporting is more important when it is about luck than about performance (Kajackaite, 2018) but we do not know whether the opponent's group identity would matter when misreporting is about performance and not about luck. Another extension could study whether variations in the nature and intensity of competition affect the impact of group identity on misreporting. 


\section{References}

Abbink, K., J. Brandts, B. Herrmann, and H. Orzen (2012). Parochial altruism in inter-group conflicts. Economics Letters 117(1), 45-48.

Abeler, J., D. Nosenzo, and C. Raymond (2019). Preferences for Truth-Telling. Econometrica. Forthcoming.

ACFE (2016). Report to the nations on occupationnal fraud and abuse. Technical report.

Akerlof, G. A. and R. E. Kranton (2000). Economics and identity. The Quarterly Journal of Economics 115(3), 715-753.

Banerjee, R., N. D. Gupta, and M. C. Villeval (2018). The spillover effects of affirmative action on competitiveness and unethical behavior. European Economic Review 101, 567-604.

Barfort, S., N. A. Harmon, F. G. Hjorth, and A. L. Olsen (2015). Dishonesty and Selection into Public Service in Denmark: Who Runs the World's Least Corrupt Public Sector? Discussion Papers 15-12, University of Copenhagen. Department of Economics.

Bent, W. (2018). Speaking Out: The State Department Needs to Reevaluate Its Use of 360-Degree Reviews. The Foreign Service Journal. Find at http://www.afsa.org/state-department-needs-reevaluateits-use-360-degree-reviews.

Bernhard, H., U. Fischbacher, and E. Fehr (2006). Parochial altruism in humans. Nature 442(7105), 912-5.

Bock, O., I. Baetge, and A. Nicklisch (2014). Hroot: Hamburg Registration and Organization Online Tool. European Economic Review 71, 117-120.

Bracken, D., C. W Timmreck, and A. Church (2001). The handbook of multisource feedback. San Francisco: Jossey-Bass.

Buchan, N. and R. Croson (2004). The boundaries of trust: Own and others' actions in the US and China. Journal of Economic Behavior and Organization 55(4), 485-504.

Cadsby, C. B., N. Du, and F. Song (2016). In-group favoritism and moral decision-making. Journal of Economic Behavior \& Organization 128, 59-71.

Carpenter, J., P. H. Matthews, and J. Schirm (2010). Tournaments and Office Politics : Evidence from a Real Effort Experiment. American Economic Review 100(1), 504-517.

Cartwright, E. and M. L. C. Menezes (2014). Cheating to win: Dishonesty and the intensity of competition. Economics Letters 122(1), 55-58.

Chakravarty, S. and S. Maximiano (2016). Deception, social preferences and friendship. Working Papers 1008, Purdue University, Department of Consumer Sciences.

Charness, G., D. Masclet, and M. C. Villeval (2014). The Dark Side of Competition for Status. Management Science 60(1), 38-55.

Charness, G., L. Rigotti, and A. Rustichini (2007). Individual Behavior and Group Membership. American Economics Review 97(4), 1340-1352.

Chen, Y., S. X. Li, and Y. Chen (2009). Group identity and social preferences. American Economic Review 97(4), 431-457.

Chen, Y., S. X. Li, T. X. Liu, and M. Shih (2014). Which hat to wear? Impact of natural identities on coordination and cooperation. Games and Economic Behavior 84, 58-86. 
Chen, Z., D. Ong, and R. M. Sheremeta (2015). Competition Between and Within Universities: eoretical and Experimental Investigation of Group Identity and the Desire to Win. MPRA Paper No. 67522.

Chowdhury, S. M. and O. Gürtler (2015). Sabotage in Contests : A Survey. Public Choice 164(1), $135-155$.

Chowdhury, S. M., J. Y. Jeon, and A. Ramalingam (2016). Identity and Group Conflict. European Economic Review 90, 107-121.

Cohn, A., E. Fehr, and M. A. Maréchal (2014). Business culture and dishonesty in the banking industry. Nature 516(7529), 86-89.

Cohn, A., M. A. Maréchal, and T. Noll (2015). Bad boys: How criminal identity salience affects rule violation. Review of Economic Studies 82(4), 1289-1308.

Conrads, J., B. Irlenbusch, R. M. Rilke, A. Schielke, and G. Walkowitz (2014). Honesty in tournaments. Economics Letters 123(1), 90-93.

Datta Gupta, N., A. Poulsen, and M. C. Villeval (2013). Gender matching and competitiveness: Experimental evidence. Economic Inquiry 51(1), 816-835.

Della Valle, N. and M. Ploner (2017). Reacting to Unfairness: Group Identity and Dishonest Behavior. Games 8(3), 28.

Dreber, A. and M. Johannesson (2008). Gender differences in deception. Economics Letters 99(1), 197-199.

Dufwenberg, M. and M. A. Dufwenberg (2018). Lies in disguise - A theoretical analysis of cheating. Journal of Economic Theory 175(175), 248-264.

Eckel, C. C. and P. J. Grossman (2005). Managing diversity by creating team identity. Journal of Economic Behavior 83 Organization 58(3), 371-392.

Efferson, C., R. Lalive, and E. Fehr (2008). The Coevolution of Cultural Groups and Ingroup Favoritism. Science 321(5897), 1844-1849.

Eriksson, T., L. Mao, and M. C. Villeval (2017). Saving face and group identity. Experimental Economics $20(3), 622-647$.

Erkal, N., L. Gangadharan, and N. Nikiforakis (2011). Relative Earnings and Giving in a Real-Effort Experiment. American Economic Review 101(7), 3330-3348.

Falk, A. and N. Szech (2013). Morals and Markets. Science 340(6133), 707-712.

Faravelli, M., L. Friesen, and L. Gangadharan (2015). Selection, tournaments, and dishonesty. Journal of Economic Behavior and Organization 110, 160-175.

Feldhaus, C. and J. Mans (2014). Who do you lie to? Social identity and the costs of lying. Working Paper Series in Economics No. 74 from University of Cologne, Department of Economics.

Feltovich, N. (2018). The interaction between competition and unethical behaviour : experimental evidence. Experimental Economics. Forthcoming.

Fischbacher, U. (2007). Z-Tree: Zurich toolbox for ready-made economic experiments. Experimental Economics 10(2), 171-178.

Fischbacher, U. and F. Föllmi-Heusi (2013). Lies in Disguise - An Experimental Study on Cheating. Journal of the European Economic Association 11(40), 525-547. 
Gächter, S. and J. F. Schulz (2016). Intrinsic honesty and the prevalence of rule violations across societies. Nature 531(7595), 496-499.

Garbarino, E., R. Slonim, and M. C. Villeval (2018). Loss aversion and lying behavior. Journal of Economic Behavior 83 Organization. In press.

Garrett, N., S. C. Lazzaro, D. Ariely, and T. Sharot (2016). The brain adapts to dishonesty. Nature Neuroscience 19, 1727-1732.

Gibson, R., C. Tanner, and A. F. Wagner (2013). Preferences for Truthfulness : Heterogeneity among and within Individuals. American Economic Review 103(1), 532-548.

Gino, F., S. Ayal, and D. Ariely (2009). Contagion and differentiation in unethical behavior: the effect of one bad apple on the barrel. Psychological Science 20(3), 393-8.

Gneezy, U., A. Kajackaite, and J. Sobel (2018). Lying Aversion and the Size of the Lie. American Economic Review 108(2).

Goette, L., D. Huffman, S. Meier, and B. L. Goette (2006). The Impact of Group Membership on Cooperation and Norm Enforcement: Evidence Using Random Assignment to Real Social Groups. American Economic Review 96(2), 212-216.

Goette, L., D. Huffman, S. Meier, and M. Sutter (2012). Competition between organizational groups : Its impact on altruistic and anti-social motivations. Management Science 58(5), 948-960.

Grosch, K. and H. A. Rau (2017). Gender differences in honesty: The role of social value orientation. Journal of Economic Psychology 62, 258-267.

Guala, F. and A. Filippin (2017). The Effect of Group Identity on Distributive Choice: Social Preference or Heuristic? Economic Journal 127(602), 1047-1068.

Guala, F., L. Mittone, and M. Ploner (2013). Group membership, team preferences, and expectations. Journal of Economic Behavior \&3 Organization 86, 183-190.

Güth, W., M. Ploner, and T. Regner (2009). Determinants of in-group bias: Is group affiliation mediated by guilt-aversion? Journal of Economic Psychology 30(5), 814-827.

Harbring, C. and B. Irlenbusch (2011, mar). Sabotage in Tournaments: Evidence from a Laboratory Experiment. Management Science 57(4), 611-627.

Harbring, C., B. Irlenbusch, M. Kräkel, and R. Selten (2007). Sabotage in Corporate Contests - An Experimental Analysis. International Journal of the Economics of Business 14(3), 367-392.

Hargreaves Heap, S. P. and D. J. Zizzo (2009). The Value of Groups. American Economic Review 99(1), $295-323$.

Hruschka, D., C. Efferson, T. Jiang, A. Falletta-Cowden, S. Sigurdsson, R. McNamara, M. Sands, S. Munira, E. Slingerland, and J. Henrich (2014). Impartial Institutions, Pathogen Stress and the Expanding Social Network. Human Nature 25(4), 567-579.

Jiang, T. (2015). Other-regarding Preferences and Other-regarding Cheating - Experimental Evidence from China, Italy and the Netherlands. Mimeo.

Kajackaite, A. (2018). Lying about luck versus lying about performance. Journal of Economic Behavior and Organization 153, 194-199.

Kajackaite, A. and U. Gneezy (2017). Incentives and cheating. Games and Economic Behavior 102, $433-444$. 
Kantor, J. and D. Streitfeld (2015). Inside Amazon: Wrestling Big Ideas in a Bruising Workplace. New York Times.

Kato, T., S. Pian, and P. Shu (2016). Competition and social identity in the workplace: Evidence from a Chinese textile firm. Journal of Economic Behavior and Organization 131(Part A), 37-50.

Khalmetski, K. and D. Sliwka (2017). Disguising Lies - Image Concerns and Partial Lying in Cheating Games. CESifo Working Paper no. 6347.

Kilduff, G. J., A. D. Galinsky, E. Gallo, and J. J. Reade (2016). Whatever It Takes To Win: Rivalry Increases Unethical Behavior. Academy of Management Journal 59(5), 1508-1534.

Kolmar, M. and A. Wagener (2012). Group Identities in Conflicts. Working Paper, University of St. Gallen.

Konrad, K. A. (2000). Sabotage in Rent-seeking Contests. Journal of Law, Economics 8 S Organization 16(1), 155-165.

Lazear, E. P. (1989). Pay equality and Industrial Politics. Journal of Political Economy 97(3), 561-580.

Lazear, E. P. and S. Rosen (1981). Rank-Order Tournaments as Optimum Labor Contracts. Journal of Political Economy 89(5), 841-864.

Lepsinger, R. and A. D. Lucia (2009). The Art and Science of 360-Degree Feedback (2nd editio ed.).

Li, S. X. and T. X. Liu (2017). Group Identity and Cooperation in Infinitely Repeated Games. Mimeo.

López-Pérez, R. and E. Spiegelman (2013). Why do people tell the truth? Experimental evidence for pure lie aversion. Experimental Economics 16(3), 233-247.

Lundquist, T., T. Ellingsen, E. Gribbe, and M. Johannesson (2009). The aversion to lying. Journal of Economic Behavior and Organization 70(1-2), 81-92.

Mazar, N., O. Amir, and D. Ariely (2008). The Dishonesty of Honest People: A Theory of Self-Concept Maintenance. Journal of Marketing Research 45(6), 633-644.

Mcleish, K. N. and R. J. Oxoby (2011). Social Interactions and the Salience of Social Identity. Journal of Economic pscychology 32(1), 172-178.

Meub, L., T. Proeger, T. Schneider, and K. Bizer (2016). The victim matters - experimental evidence on lying, moral costs and moral cleansing. Applied Economics Letters 23(16), 1162-1167.

Muehlheusser, G., A. Roider, and N. Wallmeier (2015). Gender differences in honesty: Groups versus individuals. Economics Letters 128, 25-29.

Murphy, R. O., K. A. Ackermann, and M. J. J. Handgraaf (2011). Measuring Social Value Orientation. Judgment and Decision Making 6(8), 771-781.

Nieken, P. and S. Dato (2016). Compensation and Honesty: Gender Differences in Lying.

Ockenfels, A. and P. Werner (2014). Beliefs and ingroup favoritism. Journal of Economic Behavior and Organization 108, 453-462.

Pittarello, A., E. Rubaltelli, and R. Rumiati (2013). You can't be better than me: The role of the reference point in modulating people's pursuit of wealth. Journal of Economic Psychology 37, 65-76.

Potters, J. and J. Stoop (2016). Do cheaters in the lab also cheat in the field? European Economic Review 87, 26-33. 
Rigdon, M. L. and A. D'Esterre (2015). The Effects of Competition on the Nature of Cheating Behavior. Southern Economic Journal 81.

Ruffle, B. J. and R. Sosis (2006). Cooperation and the in-group-out-group bias: A field test on Israeli kibbutz members and city residents. Journal of Economic Behavior and Organization 60(2), 147-163.

Schurr, A. and I. Ritov (2016). Winning a competition predicts dishonest behavior. Proceedings of the National Academy of Sciences 113(7), 201515102.

Schwieren, C. and D. Weichselbaumer (2010). Does competition enhance performance or cheating? A laboratory experiment. Journal of Economic Psychology 31(3), 241-253.

Shalvi, S. and C. K. W. De Dreu (2014). Oxytocin promotes group-serving dishonesty. Proceedings of the National Academy of Sciences 111(15), 5503-5507.

Shleifer, A. (2004). Does competition destroy Ethical Behavior? American Economic Review 94(2), $414-418$.

Tajfel, H. and J. Turner (1979). An Integrative Theory of Intergroup Conflict. Monterey, CA: BrooksCole.

Tullock, G. (1980). Efficient Rent-Seeking: Toward a Theory of the Rent Seeking Society. Texas A\&M University Press.

Weber, E. U., A.-R. A.-R. Blais, and N. E. Betz (2002). A domain-specific risk-attitude scale: Measuring risk perceptions and risk behaviors. Journal of Behavioral Decision Making 15, 263-290.

Yamagishi, T. and N. Mifune (2008). Does Shared Group Membership Promote Altruism? Rationality and Society 20(1), 5-30. 


\title{
A Instructions
}

\author{
Instructions for the No Identity treatment (translated from French)
}

Thank you for participating in this experiment on decision making. Please do not communicate with the others participants until the end of the session. In this session, all your decisions are kept anonymous.

During the experiment, the transactions will be made in ECUs (Experimental Currency Units) and not in Euros. All your earnings will be expressed in ECUs. At the end of the experiment, the total amount of ECUs you have earned will be converted into Euros at the following rate:

$$
100 \text { ECUs }=2.5 \text { Euros }
$$

You will also receive a 5 Euros show-up fee. Your total earnings will be paid to you in cash at the end of the session. The payments will be made privately in a separate room. The other participants will not be informed of your earnings.

The session consists of three parts. You will receive the instructions for each part after having completed the previous part.

Each of you has completed an online questionnaire before participating in this session. An ID was sent to you by email to keep your answers to this questionnaire anonymous. You will be asked to enter this ID into your computer at the very beginning of the session. Your earnings in this preliminary part have been computed and they will be paid to you at the end of this session.

\section{Part 1}

\section{General description}

This part consists of 16 periods in which you will have to perform a task. In each period your task consists in solving problems during 30 seconds. Each problem solved increases your "subscore" by one point.

In each period, you are randomly matched with another participant. Thus, it is very unlikely that you are matched with the same participant twice in a row.

At the end of the period, a participant in the pair earns 100 ECUs and the other earns 50 ECUs. Your payoff depends on your "final score" relative to the final score of the other participant. Your final score consists of two elements: your subscore plus a random number that you or the other participant have to report. If your final score is higher than the final score of the other participant, the higher is the difference between your final score and the other participant's final score, the more likely you will get 100 ECUs.

At the end of the session, two periods among the 16 will be randomly selected by the program to determine your earnings in this part.

\section{Description of each period}

A period consists of 4 stages.

- Stage 1: the task 
You have to perform a task during 30 seconds. This task consists in decoding letters into numbers. A conversion table is displayed permanently on your screen. After having decoded the displayed letter, you have to press the OK button to validate your answer. You are immediately informed of whether your answer is correct or not. If your answer is incorrect, you have to enter another number. The next problem will be displayed only after you have entered a correct answer. If your answer is correct, a new letter is displayed and this will continue for 30 seconds. The conversion table changes in each period. It is the same for all the participants.

- Stage 2: matching pairs and information

The program forms pairs randomly. You are informed about your subscore and the subscore of the other participant. The other participant receives the same information as you.

- Stage 3: final score of the period

Your final score is determined by the sum of your subscore and the reported random number.

The program selects independently a random number for you and a random number for the other participant (with rebate). The random numbers are integers between -5 and 5 . You are informed about your random number and the other participant's random number. You have to memorize these numbers because you will be asked to report one of them on the following screen in order to determine your final scores.

Depending on the period, one of the two following cases occurs:

- Case 1: you have to report your own random number. The other participant reports his own random number.

- Case 2: you have to report the random number of the other participant. The other participant has to report your random number.

Once the random numbers have been reported, the program computes your final score and the other participant's final score. The final scores are determined differently in the two cases.

In case 1, your final score is equal to your subscore (the number of problems solved) plus your random number as reported by yourself. The computation is the same for the other participant.

Case 1: Your final score $=$ your subscore + your random number as reported by yourself Other participant's final score $=$ his subscore + his random number as reported by himself

In case 2, your final score is equal to your subscore (the number of problems solved) plus your random number as reported by the other participant. The computation is the same for the other participant. 
Case 2: Your final score $=$ your subscore + your random number as reported by the other participant

Other participant's final score $=$ his subscore + his random number as reported by yourself

- Stage 4: Determination of the payoff of the period

The higher is your final score relative to the final score of the other participant, the more likely you will earn 100 ECUs. The lower is your final score relative to the final score of the other participant, the more likely you will earn 50 ECUs.

More precisely, your chance of winning 100 ECUs is determined as follows:

$$
\text { Your chance of winning } 100 \mathrm{ECUs}=\frac{\text { Your final score }}{\text { Your final score }+ \text { other participant's final score }}
$$

This formula indicates that for your given final score, if the other participant's final score increases, your chance to win 100 ECUs decreases. In contrast, for a given final score of the other participant, if your final score increases, your chance to win 100 ECUs also increases. Your chance to win depends on your final score but also on the final score of the other participant, and the same logic applies to him.

- End of the period

- In case 1, you are informed of your final score. You are not informed of the final score of the other participant.

- In case 2, you are informed of the final score of the other participant. You are not informed of your final score.

In both cases, you are informed of your payoff, either 50 ECUs or 100 ECUs.

The next period starts automatically. You have to perform the same task and new pairs are formed.

\section{Summary}

In each period:

- You solve problems during 30 seconds.

- You are randomly matched with another participant.

- You are informed about your subscore and the subscore of this other participant.

- You are informed about your random number and the other participant's random number.

- You report one of the two random numbers, depending on the period.

- You are informed of your payoff and of your final score, or of the final score of the other participant, depending on the period.

Just before the end of the session, there will be a last stage. The instructions will be displayed on your screen. At this time, do not hesitate to ask questions by raising your hand and/or by pressing the red button.

\section{Part 2}

The instructions for this part will be directly displayed on your screen. If you have questions at this time, do not hesitate to ask questions by raising your hand and/or by pressing the red button. 


\section{End of the session}

At the end of the session, your screen will display the following information:

- The two periods selected in part 1 and your earnings for this part.

- Your earnings for the second part.

- Your total earnings for the session.

Your earnings for the online part and the show-up fee will be added to the earnings of the session. The payment will be made by someone who does not know the content of the session and has no access to the program and the data. 


\section{Instructions for the Identity treatment (translated from French)}

Thank you for participating in this experiment on decision making. Please do not communicate with the others participants until the end of the session. In this session, all your decisions are kept anonymous.

During the experiment, the transactions will be made in ECUs (Experimental Currency Units) and not in Euros. All your earnings will be expressed in ECUs. At the end of the experiment, the total amount of ECUs you have earned will be converted into Euros at the following rate:

$$
100 \text { ECUs }=2.5 \text { Euros }
$$

You will also receive a 5 Euros show-up fee. Your total earnings will be paid to you in cash at the end of the session. The payments will be made privately in a separate room. The other participants will not be informed of your earnings.

The session consists of three parts. You will receive the instructions for each part after having completed the previous part.

Each of you has completed an online questionnaire before participating in this session. An ID was sent to you by email to keep your answers to this questionnaire anonymous. You will be asked to enter this ID into your computer at the very beginning of the session. Your earnings in this preliminary part have been computed and they will be paid to you at the end of this session.

\section{Part 1}

At the beginning of this part and for the rest of the session, participants are divided into two groups of equal size. Each group bears the name of an artist: Klee or Kandinsky. You will be classified into one of the two groups, based on which painter you prefer.

The following procedure is used to determine to which group you will belong to.

Your screen will display five pairs of painting successively. In each pair, one painting was painted by Klee and the other one by Kandinsky. We will ask you to choose which one you prefer in each pair.

Then, you will be matched with people who have the closest preferences from yours. The program will assign each participant to either the Klee group or the Kandinsky group, in order to form two groups of equal size. Having a stronger preference for the paintings of a given artist will increase the likelihood to be assigned to this group. If there are too many participants in one group, those who had the weakest preference for this artist will be assigned to the other group.

Then, you will be informed of which group you belong to. During the rest of the task, you will remain in the same group.

In a second stage, two more paintings will be displayed on your screen. You will have to select the artist who you think made each painting. Each correct answer pays 50 ECUs.

Before entering your answers, you will have access to a chat program to get help from or offer help to other members of your group. You will not be able to communicate with members of the other group. For example, if you are a member of the Klee group you will only be able to chat with the others members of the Klee group, and conversely if you belong to the Kandinsky group. To chat, you have to write your message in the bottom part of the chat box and press enter to validate. 
You will be given 8 minutes to access the chat program. Once the 8 minutes have elapsed, a new screen will be displayed in which you will have to enter your answers, individually. You will be informed of your payoff for this part at the end of the session. If you have questions about these instructions, please raise your hand or press the red button on the side of your desk. We will answer to your questions in private. 


\section{Part 2}

This part consists of five periods. In each period you will receive a certain endowment in ECUs. The amount varies from period to period. You will be asked to allocate these ECUs between two other participants (called Person A and Person B) under three scenarios:

- Scenario 1: both are from your own group

- Scenario 2: both are from the other group

- Scenario 3: one is from your group, and one is from the other group.

For each scenario you must allocate your entire endowment between the two participants. Allocations have to be integers. Do not allocate any ECU to yourself. Your decisions will be used to determine other participants' payoffs for this part at the end of the session. Similarly, your payoff for this part will be determined by others decisions.

A screenshot is reproduced below.

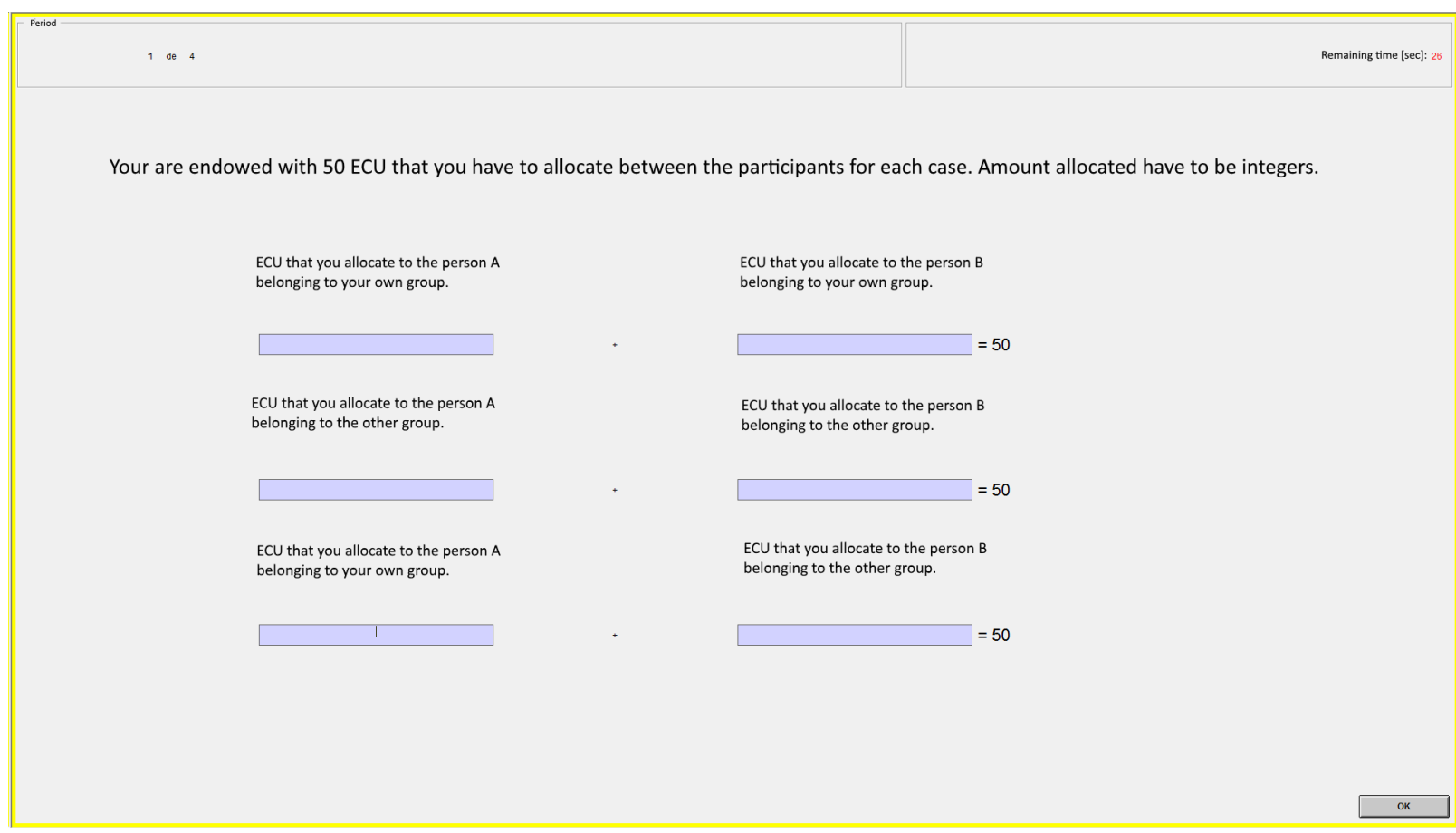

At the end of the session, the program will randomly select a period that is used to calculate the payoffs. Each period of decision will have an equal chance of being selected. For the selected period, a new random draw will determine which scenario will be used to calculate the payoffs. Then, the program will randomly select two participants. The allocation for Person A made by the first participant and the decision for Person B made by the second participant will be added to determine your payoff.

Depending on the random draw the selected participants can be from your group or not. If the first scenario is selected, the two participants will be from your group. If the second scenario is selected, the two participants will be from the other group. If the third scenario is selected, the first participant will be from your group and the second one from the other group.

You will be informed of your payoff for this part at the end of the session.

After reading again these instructions, if you have any questions please raise your and/or press the red button. 


\section{Part 3}

\section{General description}

This part consists of 16 periods in which you will have to perform a task. In each period your task consists in solving problems during 30 seconds. Each problem solved increases your "subscore" by one point.

In each period, you are randomly matched with another participant. Thus, it is very unlikely that you are matched with the same participant twice in a row.

At the end of the period, a participant in the pair earns 100 ECUs and the other earns 50 ECUs. Your payoff depends on your "final score" relative to the final score of the other participant. Your final score consists of two elements: your subscore plus a random number that you or the other participant have to report. If your final score is higher than the final score of the other participant, the higher is the difference between your final score and the other participant's final score, the more likely you will get 100 ECUs.

At the end of the session, two periods among the 16 will be randomly selected by the program to determine your earnings in this part.

\section{Description of each period}

A period consists of 4 stages.

- Stage 1: the task

You have to perform a task during 30 seconds. This task consists in decoding letters into numbers. A conversion table is displayed permanently on your screen. After having decoded the displayed letter, you have to press the OK button to validate your answer. You are immediately informed of whether your answer is correct or not. If your answer is incorrect, you have to enter another number. The next problem will be displayed only after you have entered a correct answer. If your answer is correct, a new letter is displayed and this will continue for 30 seconds. The conversion table changes in each period. It is the same for all the participants.

- Stage 2: matching pairs and information

The program forms pairs randomly. You are informed of the other participant's group (Klee or Kandinsky). Then, you are informed about your subscore and the subscore of the other participant. The other participant receives the same information as you.

- Stage 3: final score of the period

Your final score is determined by the sum of your subscore and the reported random number.

The program selects independently a random number for you and a random number for the other participant (with rebate). The random numbers are integers between -5 and 5 . You are informed about your random number and the other participant's random number. You have to memorize these numbers because you will be asked to report one of them on the following screen in order to determine your final score.

Depending on the period, one of the two following cases occurs:

- Case 1: you have to report your own random number. The other participant reports his own random number. 
- Case 2: you have to report the random number of the other participant. The other participant has to report your random number.

Once the random numbers have been reported, the program computes your final score and the other participant's final score. The final scores are determined differently in the two cases.

In case 1, your final score is equal to your subscore (the number of problems solved) plus your random number as reported by yourself. The computation is the same for the other participant.

Case 1: Your final score $=$ your subscore + your random number as reported by yourself Other participant's final score $=$ his subscore + his random number as reported by himself

In case 2, your final score is equal to your subscore (the number of problems solved) plus your random number as reported by the other participant. The computation is the same for the other participant.

Case 2: Your final score $=$ your subscore + your random number as reported by the other participant

Other participant's final score $=$ his subscore + his random number as reported by yourself

- Stage 4: Determination of the payoff of the period

The higher is your final score relative to the final score of the other participant, the more likely you will earn 100 ECUs. The lower is your final score relative to the final score of the other participant, the more likely you will earn 50 ECUs.

More precisely, your chance of winning 100 ECUs is determined as follows:

Your chance of winning $100 \mathrm{ECUs}=\frac{\text { Your final score }}{\text { Your final score }+ \text { other participant's final score }}$

This formula indicates that for your given final score, if the other participant's final score increases, your chance to win 100 ECUs decreases. In contrast, for a given final score of the other participant, if your final score increases, your chance to win 100 ECUs also increases. Your chance to win depends on your final score but also on the final score of the other participant, and the same logic applies to him.

- End of the period

- In case 1, you are informed of your final score. You are not informed of the final score of the other participant.

- In case 2, you are informed of the final score of the other participant. You are not informed of your final score.

In both cases, you are informed of your payoff, either 50 ECUs or 100 ECUs.

The next period starts automatically. You have to perform the same task and new pairs are formed. 


\section{Summary}

In each period:

- You solve problems during 30 seconds.

- You are randomly matched with another participant.

- You are informed about the group of the other participant and about your subscore and the subscore of this other participant.

- You are informed about your random number and the other participant's random number.

- You report one of the two random numbers, depending on the period.

- You are informed of your payoff and of your final score, or of the final score of the other participant, depending on the period.

Just before the end of the session, there will be a last stage. The instructions will be displayed on your screen. At this time, do not hesitate to ask questions by raising your hand and/or by pressing the red button.

\section{End of the session}

At the end of the session, your screen will display the following information:

- Your earnings for part 1.

- The period and the case selected for the computation of your earnings in part 2 and your earnings for this part.

- The two periods selected in part 3 and your earnings for this part.

- Your earnings for the last stage.

- Your total earnings for the session.

Your earnings for the online part and the show-up fee will be added to the earnings of the session. The payment will be made by someone who does not know the content of the session and has no access to the program and the data. 
Instructions for the Identity-No-Scrutiny treatment (translated from French)

The instructions for part 1, part 2 and for the end of the session are similar to the Identity treatment. They are omitted here.

\section{Part 3}

\section{General description}

This part consists of 16 periods in which you will have to perform a task. In each period your task consists in solving problems during 30 seconds. Each problem solved increases your "subscore" by one point.

In each period, you are randomly matched with another participant. Thus, it is very unlikely that you are matched with the same participant twice in a row.

At the end of the period, a participant in the pair earns 100 ECUs and the other earns 50 ECUs. Your payoff depends on your "final score" relative to the final score of the other participant. Your final score consists of two elements: your subscore plus a random number that you or the other participant have to report. If your final score is higher than the final score of the other participant, the higher is the difference between your final score and the other participant's final score, the more likely you will get 100 ECUs.

At the end of the session, two periods among the 16 will be randomly selected by the program to determine your earnings in this part.

\section{Description of each period}

A period consists of 4 stages.

- Stage 1: the task

You have to perform a task during 30 seconds. This task consists in decoding letters into numbers. A conversion table is displayed permanently on your screen. After having decoded the letter displayed letter, you have to press the OK button to validate your answer. You are immediately informed of whether your answer is correct or not. If your answer is incorrect, you have to enter another number. The next problem will be displayed only after you have entered a correct answer. If your answer is correct, a new letter is displayed and this will continue for 30 seconds. The conversion table changes in each period. It is the same for all the participants. Each letter correctly encoded increases your subscore by 1 point.

- Stage 2: matching pairs and information

The program forms pairs randomly. You are informed of the other participant's group (Klee or Kandinsky). Then, you are informed about your subscore and the subscore of the other participant. The other participant receives the same information as you.

- Stage 3: final score of the period

Your final score is determined by the sum of your subscore and the reported random number.

The random number is determined by the following procedure.

- On a first screen you will be asked to choose, in your head, a letter between A and K. You will have to memorize this letter. Then, the program will determine 
independently a random set of 11 integer numbers. This set contains all integers between -5 and +5 , sorted out in a random order. Each letter between $\mathrm{A}$ and $\mathrm{K}$ will be matched with a different number. The table below displays an example of set.

$$
\begin{array}{ccccccccccc}
\mathrm{A} & \mathrm{B} & \mathrm{C} & \mathrm{D} & \mathrm{E} & \mathrm{F} & \mathrm{G} & \mathrm{H} & \mathrm{I} & \mathrm{J} & \mathrm{K} \\
\hline 3 & -3 & -2 & -5 & 2 & 0 & -4 & 4 & -1 & 5 & 1
\end{array}
$$

- Then, depending on the period, one of the two following cases occurs

* Case 1: On a new screen, you will be informed on the set of numbers randomly drawn for you in the period. You will not know the set of numbers of the other participant and the other participant will not know your set of numbers. You will be asked to report the number which corresponds to the letter you chose in your head and had to keep in mind. For example, if you chose the letter E, you have to report the number located in the 5th rank in the set starting from the left. In the example above, it corresponds to the number 2. The other participant will have to report the number corresponding to the letter he has chosen and kept in his mind.

* Case 2: On a new screen, you will be informed on the set of numbers randomly drawn for the other participant in the period. You will not know the set of numbers drawn for you and the other participant will not know his set of numbers. You will be asked to report the number which corresponds to the letter you chose in your head and had to keep in mind. The other participant will have to report the number corresponding to the letter he has chosen and kept in his mind.

Once the random numbers have been reported, the program computes your final score and the other participant's final score. The final scores are determined differently in the two cases.

In case 1, your final score is equal to your subscore (the number of problems solved) plus the random number reported by yourself. The computation is the same for the other participant.

Case 1: Your final score $=$ your subscore + the random number as reported by yourself Other participant's final score $=$ his subscore + the random number as reported by himself

In case 2, your final score is equal to your subscore (the number of problems solved) plus the random number reported by the other participant. The computation is the same for the other participant.

Case 2: Your final score $=$ your subscore + the random number as reported by the other participant

Other participant's final score $=$ his subscore + the random number as reported by yourself

- Stage 4: Determination of the payoff of the period

The higher is your final score relative to the final score of the other participant, the more likely you will earn 100 ECUs. The lower is your final score relative to the final score of the other participant, the more likely you will earn 50 ECUs. 
More precisely, your chance of winning 100 ECUs is determined as follows:

Your chance of winning $100 \mathrm{ECUs}=\frac{\text { Your final score }}{\text { Your final score }+ \text { other participant's final score }}$

This formula indicates that for your given final score, if the other participant's final score increases, your chance to win 100 ECUs decreases. In contrast, for a given final score of the other participant, if your final score increases, your chance to win 100 ECUs also increases. Your chance to win depends on your final score but also on the final score of the other participant, and the same logic applies to him.

- End of the period

- In case 1, you are informed of your final score. You are not informed of the final score of the other participant.

- In case 2, you are informed of the final score of the other participant. You are not informed of your final score.

In both cases, you are informed of your payoff, either 50 ECUs or 100 ECUs.

The next period starts automatically. You have to perform the same task and new pairs are formed.

\section{Summary}

In each period:

- You solve problems during 30 seconds.

- You are randomly matched with another participant.

- You are informed about the group of the other participant and about your subscore and the subscore of this other participant.

- You have to choose in your head a letter between A and K

- You are informed either about your random set of numbers or about the other participant's random set of numbers, depending on the period

- You report the random number which corresponds to the letter you previously chose in your head

- You are informed of your payoff and of your final score, or of the final score of the other participant, depending on the period

Just before the end of the session, there will be a last stage. The instructions will be displayed on your screen. At this time, do not hesitate to ask questions by raising your hand and/or by pressing the red button.

\section{End of the session}

At the end of the session, your screen will display the following information:

- Your earnings for part 1.

- The period and the case selected for the computation of your earnings in part 2 and your earnings for this part.

- The two periods selected in part 3 and your earnings for this part.

- Your earnings for the last stage.

- Your total earnings for the session.

Your earnings for the online part and the show-up fee will be added to the earnings of the session. The payment will be made by someone who does not know the content of the session and has no access to the program and the data. 
Instructions for the Identity-No-Info treatment (translated from French)

The instructions for part 1, part 2 and for the end of the session are similar to the Identity treatment. They are omitted here.

\section{Part 3}

\section{General description}

This part consists of 16 periods in which you will have to perform a task. In each period your task consists in solving problems during 30 seconds. Each problem solved increases your "subscore" by one point.

In each period, you are randomly matched with another participant. Thus, it is very unlikely that you are matched with the same participant twice in a row.

At the end of the period, a participant in the pair earns 100 ECUs and the other earns 50 ECUs. Your payoff depends on your "final score" relative to the final score of the other participant. Your final score consists of two elements: your subscore plus a random number that you or the other participant have to report. If your final score is higher than the final score of the other participant, the higher is the difference between your final score and the other participant's final score, the more likely you will get 100 ECUs.

At the end of the session, two periods among the 16 will be randomly selected by the program to determine your earnings in this part.

\section{Description of each period}

A period consists of 4 stages.

- Stage 1: the task

You have to perform a task during 30 seconds. This task consists in decoding letters into numbers. A conversion table is displayed permanently on your screen. After having decoded the letter displayed, you have to press the OK button to validate your answer. You are immediately informed of whether your answer is correct or not. If your answer is incorrect, you have to enter another number. The next problem will be displayed only after you have entered a correct answer. If your answer is correct, a new letter is displayed and this will continue for 30 seconds. The conversion table changes in each period. It is the same for all the participants. Each letter correctly encoded increases your subscore by 1 point.

- Stage 2: matching pairs and information

The program forms pairs randomly. You are informed of the other participant's group (Klee or Kandinsky). Then, you are informed about your subscore and the subscore of the other participant. The other participant receives the same information as you.

- Stage 3: final score of the period

Your final score is determined by the sum of your subscore and the reported random number.

The program selects independently a random number for you and a random number for the other participant (with rebate). The random numbers are integers between -5 and 5. You are informed either of your random number or of the other participant's random number. You have to memorize these numbers because you will be asked to report them on the following screen in order to determine the final score. 
Depending on the period, one of the two following cases occurs:

- Case 1: you have to report your own random number. The other participant reports his own random number. You are not informed of the other participant's random number and he is not informed of your random number.

- Case 2: you have to report the random number of the other participant. The other participant has to report your random number. You are not informed of your random number and he is not informed of his random number.

Once the random numbers have been reported, the program computes your final score and the other participant's final score. The final scores are determined differently in the two cases.

In case 1, your final score is equal to your subscore (the number of problems solved) plus your random number as reported by yourself. The computation is the same for the other participant.

Case 1: Your final score $=$ your subscore + your random number as reported by yourself

Other participant's final score $=$ his subscore + his random number as reported by himself

In case 2, your final score is equal to your subscore (the number of problems solved) plus your random number as reported by the other participant. The computation is the same for the other participant.

Case 2: Your final score $=$ your subscore + your random number as reported by the other participant

Other participant's final score $=$ his subscore + his random number as reported by yourself

- Stage 4: Determination of the payoff of the period

The higher is your final score relative to the final score of the other participant, the more likely you will earn 100 ECUs. The lower is your final score relative to the final score of the other participant, the more likely you will earn 50 ECUs.

More precisely, your chance of winning 100 ECUs is determined as follows:

Your chance of winning $100 \mathrm{ECUs}=\frac{\text { Your final score }}{\text { Your final score }+ \text { other participant's final score }}$

This formula indicates that for your given final score, if the other participant's final score increases, your chance to win 100 ECUs decreases. In contrast, for a given final score of the other participant, if your final score increases, your chance to win 100 ECUs also increases. Your chance to win depends on your final score but also on the final score of the other participant, and the same logic applies to him.

- End of the period

- In case 1, you are informed of your final score. You are not informed of the final score of the other participant. 
- In case 2, you are informed of the final score of the other participant. You are not informed of your final score.

In both cases, you are informed of your payoff, either 50 ECUs or 100 ECUs.

The next period starts automatically. You have to perform the same task and new pairs are formed.

\section{Summary}

In each period:

- You solve problems during 30 seconds.

- You are randomly matched with another participant.

- You are informed about the group of the other participant and about your subscore and the subscore of this other participant.

- You are informed either of your random number or of the other participant's random number.

- You report one of the two random numbers, depending on the period.

- You are informed of your payoff and of your final score, or of the final score of the other participant, depending on the period.

Just before the end of the session, there will be a last stage. The instructions will be displayed on your screen. At this time, do not hesitate to ask questions by raising your hand and/or by pressing the red button.

\section{End of the session}

At the end of the session, your screen will display the following information:

- Your earnings for part 1.

- The period and the case selected for the computation of your earnings in part 2 and your earnings for this part.

- The two periods selected in part 3 and your earnings for this part.

- Your earnings for the last stage.

- Your total earnings for the session.

Your earnings for the online part and the show-up fee will be added to the earnings of the session. The payment will be made by someone who does not know the content of the session and has no access to the program and the data. 


\section{B Tables}

Table B.1: Characteristics of participants, by treatment

Main treatments

\begin{tabular}{lcccc}
\hline & $\begin{array}{c}\text { No-Identity } \\
\text { treatment (a) }\end{array}$ & $\begin{array}{c}\text { Identity } \\
\text { treatment (b) }\end{array}$ & Test & $\begin{array}{c}\text { p-value } \\
\text { (a) vs. (b) }\end{array}$ \\
\hline Average nb of participations & $4.17(0.41)$ & $3.66(0.27)$ & Unpaired t-test & 0.288 \\
Average age & $25.11(1.07)$ & $23.42(0.51)$ & Mann-Whitney & 0.632 \\
Pro-self in SVO test (\%) & $59.37 \%$ & $50.78 \%$ & Proportion test & 0.260 \\
Male (\%) & $42.19 \%$ & $39.06 \%$ & Proportion test & 0.677 \\
Student (\%) & $71.87 \%$ & $80.47 \%$ & Proportion test & 0.178 \\
Employed (\%) & $14.06 \%$ & $12.50 \%$ & Proportion test & 0.762 \\
Unemployed (\%) & $9.37 \%$ & $4.69 \%$ & Proportion test & 0.206 \\
Other (\%) & $4.69 \%$ & $2.34 \%$ & Proportion test & 0.379 \\
Number of subjects & 64 & 128 & & \\
\hline
\end{tabular}

Note: Standard deviations are in parentheses.

Additional treatments

\begin{tabular}{|c|c|c|c|c|c|}
\hline & $\begin{array}{l}\text { Identity-No } \\
\text { Scrutiny } \\
\text { treatment (c) }\end{array}$ & $\begin{array}{l}\text { Identity-No- } \\
\text { Info } \\
\text { treatment (d) }\end{array}$ & $\begin{array}{l}\text { p-value } \\
\text { (c) vs. (d) }\end{array}$ & $\begin{array}{l}\text { p-value } \\
\text { (c) vs. (b) }\end{array}$ & $\begin{array}{l}\text { p-value } \\
\text { (d) vs. (b) }\end{array}$ \\
\hline Average nb of participations & $3.88(0.35)$ & $3.2(0.27)$ & 0.128 & 0.613 & 0.229 \\
\hline Average age & $21.71(0.41)$ & $21.18(0.17)$ & 0.706 & $<0.001$ & $<0.001$ \\
\hline Pro-self in SVO test (\%) & $28.8 \%$ & $30.0 \%$ & 0.856 & $<0.001$ & 0.002 \\
\hline Male $(\%)$ & $48.1 \%$ & $44.0 \%$ & 0.559 & 0.168 & 0.452 \\
\hline Student (\%) & $93.3 \%$ & $100.0 \%$ & 0.008 & 0.005 & $<0.001$ \\
\hline Employed (\%) & $1.0 \%$ & . & . & . & . \\
\hline Unemployed (\%) & $4.8 \%$ & . & . & . & . \\
\hline Other $(\%)$ & $1 \%$ & & . & & . \\
\hline Number of subjects & 104 & 100 & & & \\
\hline
\end{tabular}

Note: Standard deviations are in parentheses. 
Table B.2: Determinants of performance

\begin{tabular}{l|ccc}
\hline Dependent variable: & All & No-Identity & Identity \\
Subscore & $(1)$ & $(2)$ & $(3)$ \\
\hline Identity treatment & 0.101 & - & - \\
& $(0.322)$ & & \\
Opp-condition in t-1 & $0.177^{* *}$ & 0.028 & $0.230^{* * *}$ \\
& $(0.056)$ & $(0.089)$ & $(0.070)$ \\
In-group opponent in t-1 & - & - & 0.023 \\
Contest lost in t-1 & & & $(0.064)$ \\
& $0.117^{* *}$ & 0.028 & 0.136 \\
Contest lost in t-1* Opp-condition in t-1 & $(0.055)$ & $(0.089)$ & $(0.085)$ \\
& -0.126 & -0.045 & $-0.167^{*}$ \\
Contest lost in t-1* In-group opponent in t-1 & $(0.077)$ & $(0.134)$ & $(0.094)$ \\
& - & - & -0.017 \\
Period & & & $(0.064)$ \\
Period squared & $0.301^{* * *}$ & $0.229^{* * *}$ & $0.329^{* *}$ \\
SVO angle & $(0.025)$ & $(0.047)$ & $(0.029)$ \\
& $-0.012^{* * *}$ & $-0.008^{* * *}$ & $-0.013^{* * *}$ \\
Male & $(0.001)$ & $(0.002)$ & $(0.001)$ \\
Constant & -0.005 & -0.010 & -0.002 \\
& $(0.005)$ & $(0.007)$ & $(0.007)$ \\
Other individual characteristics & $0.256^{*}$ & 0.274 & 0.229 \\
Session fixed effects & $(0.143)$ & $(0.231)$ & $(0.184)$ \\
\hline Number of observations & $6.781^{* * *}$ & $7.099^{* * *}$ & $6.844^{* * *}$ \\
Number of clusters & $(0.383)$ & $(0.551)$ & $(0.392)$ \\
Chi2 $>$ Chi2 & $Y e s$ & $Y e s$ & $Y e s$ \\
& $Y e s$ & $Y e s$ & $Y e s$ \\
\hline & 2880 & 960 & 1920 \\
& 192 & 64 & 128 \\
& 422.435 & 121.290 & 374.252 \\
& $<0.001$ & $<0.001$ & $<0.001$ \\
\hline
\end{tabular}

Notes: This Table reports marginal effects from random-effects GLS regressions with robust standard errors clustered at the subject level in parentheses. The dependent variable is the subscore in $\mathrm{t}$. ${ }^{* * *}$ indicate significance at the $1 \%$ level, ${ }^{* *}$ at the $5 \%$ level, and ${ }^{*}$ at the $10 \%$ level.

Table B.2 reports an OLS regression analysis in which the dependent variable is the subscore in $t$ in the real effort task. The three models pool the Self- and Opp-conditions since subjects were not aware of the condition when they performed the task (they were informed only after performing the task). Model (2) includes only the No-Identity treatment and model (3) only the Identity treatment.

In model (1), the independent variables include dummy variables for the Identity treat- 
ment and for the Opp-condition in $t-1$, taking the Self-condition and the No-Identity treatment as the reference categories. They also include a dummy variable indicating whether the subject lost or won the contest in $t-1$ and an interaction term between the outcome of the competition in $t-1$ and being in the Opp-condition in $t-1$. We add a time trend and its squared value. We also include the subject's gender, SVO angle, age and number of past participations in a laboratory experiment. We add session fixed effects. In model (3) we also include an interaction term between the outcome of the competition in $t-1$ and a dummy variable ("In-group opponent in $t-1$ ") equal to 1 if the pair members shared the same group identity in $t-1$ and 0 otherwise. We include lagged variables because when they perform the task subjects do not know yet which condition will apply in the period and, in the Identity treatment, whether they will be opposed by an in-group or by an out-group.

This Table shows that the treatment does not impact performance. Surprisingly, being in the Opp-condition in $t-1$ is associated with a significantly higher subscore in the current period although conditions are assigned randomly in each period. This is driven by the Identity treatment. Winning the contest in t-1 increases performance in the current period in model (1), but this is endogenous since the probability of winning increases in the ability level. This variable is no longer significant in models (2) and (3). We observe also a non-linear effect of time in all models: the subscore increases over time but at a decreasing pace. 
Table B.3: Frequency and intensity of non-selfish misreporting, by treatment and condition

\begin{tabular}{|c|c|c|c|c|c|}
\hline Treatment & & Condition & $\begin{array}{c}\text { Absolute } \\
\text { relative } \\
\text { frequency of } \\
\text { misreports }\end{array}$ & $\begin{array}{c}\text { Absolute } \\
\text { relative } \\
\text { frequency of } \\
\text { full misreports }\end{array}$ & $\begin{array}{c}\text { Average } \\
\text { absolute } \\
\text { intensity of } \\
\text { misreports }\end{array}$ \\
\hline \multirow{2}{*}{ No- Identity } & Self & All & $4 / 468[0.85 \%]$ & $0 / 4[-]$ & $2.75(0.75)$ \\
\hline & Opp & All & $27 / 463[5.83 \%]$ & $6 / 27[22.23 \%]$ & $3.70(0.44)$ \\
\hline \multirow{6}{*}{ Identity } & \multirow{3}{*}{ Self } & All & $7 / 926[0.76 \%]$ & $2 / 7[28.57 \%]$ & $2.57(0.84)$ \\
\hline & & In-Group opponent & $2 / 470[0.43 \%]$ & $0 / 2[-]$ & $2(0.00)$ \\
\hline & & Out-Group opponent & $5 / 456[1.10 \%]$ & $2 / 5[40.00 \%]$ & $2.8(1.20)$ \\
\hline & \multirow{3}{*}{ Opp } & All & $26 / 927[2.80 \%]$ & $7 / 26[26.92 \%]$ & $3.69(0.58)$ \\
\hline & & In-Group opponent & $15 / 457[3.28 \%]$ & $4 / 15[26.67 \%]$ & $3.53(0.80)$ \\
\hline & & Out-Group opponent & $11 / 470[2.34 \%]$ & $3 / 11[27.27 \%]$ & $3.91(0.88)$ \\
\hline
\end{tabular}

Notes: We consider only the cases in which the subject overreports his opponent's number or underreports his own number; we exclude the cases in which the subject's number was equal to -5 in the Self-condition and the opponent's number was equal to 5 in the Opp-condition. A full misreport consists of reporting the lowest possible number for self or the highest possible number for the opponent. Percentages are into brackets. The average intensity of misreports is defined as the mean absolute value of the difference between the reported number and the actual number (with standard deviations in parentheses). 
Table B.4: Determinants of selfish misreporting in the Identity-No-Info treatment

\begin{tabular}{|c|c|c|c|}
\hline $\begin{array}{l}\text { Dependent variable: } \\
\text { Selfish misreport }\end{array}$ & All conditions & Opp-condition & Self-condition \\
\hline \multirow[b]{2}{*}{ Treatment } & \multicolumn{3}{|c|}{ Identity-No-Info } \\
\hline & $(1)$ & $(2)$ & $(3)$ \\
\hline \multirow[t]{2}{*}{ In-group opponent } & -0.026 & -0.069 & 0.004 \\
\hline & $(0.024)$ & $(1.011)$ & $(0.027)$ \\
\hline \multirow[t]{2}{*}{ Self-condition } & 0.023 & - & - \\
\hline & $(0.022)$ & & \\
\hline \multirow[t]{2}{*}{ subscore $_{i, t}$} & 0.007 & 0.014 & -0.003 \\
\hline & $(0.011)$ & $(0.153)$ & $(0.011)$ \\
\hline \multirow[t]{2}{*}{ Tie: subscore $_{i, t}=$ subscore $_{j, t}$} & -0.021 & 0.016 & 0.013 \\
\hline & $(0.035)$ & $(0.202)$ & $(0.054)$ \\
\hline \multirow[t]{2}{*}{$\operatorname{Max}\left\{0\right.$, subscore $_{i, t}-$ subscore $\left._{j, t}\right\}$} & -0.015 & -0.017 & 0.002 \\
\hline & $(0.012)$ & $(0.258)$ & $(0.020)$ \\
\hline \multirow[t]{2}{*}{$\operatorname{Max}\left\{0\right.$, subscore $_{j, t}-$ subscore $\left._{i, t}\right\}$} & -0.016 & -0.006 & -0.010 \\
\hline & $(0.015)$ & $(0.056)$ & $(0.025)$ \\
\hline \multirow[t]{2}{*}{ Random number $_{i, t}$} & -0.006 & - & -0.018 \\
\hline & $(0.004)$ & & $(0.021)$ \\
\hline \multirow[t]{2}{*}{ Random number $\mathrm{Opp}_{i, t}$} & $0.010^{* *}$ & 0.012 & - \\
\hline & $(0.004)$ & $(0.198)$ & \\
\hline \multirow[t]{2}{*}{ Period } & $0.065^{* * *}$ & 0.058 & 0.066 \\
\hline & $(0.023)$ & $(1.003)$ & $(0.075)$ \\
\hline \multirow[t]{2}{*}{ Period squared } & $-0.003^{* * *}$ & -0.002 & -0.003 \\
\hline & $(0.001)$ & $(0.041)$ & $(0.004)$ \\
\hline \multirow[t]{2}{*}{ SVO Angle } & -0.003 & -0.002 & -0.003 \\
\hline & $(0.005)$ & $(0.224)$ & $(0.014)$ \\
\hline \multirow[t]{2}{*}{ Male } & 0.188 & 0.225 & 0.134 \\
\hline & $(0.174)$ & $(11.148)$ & $(0.241)$ \\
\hline Other individual characteristics & Yes & $Y e s$ & Yes \\
\hline Number of observations & 1417 & 703 & 710 \\
\hline Number of clusters & 100 & 99 & 100 \\
\hline Pseudo-loglikelihood & -365.046 & -206.925 & -216.402 \\
\hline Wald Chi2 & 77.232 & 92.399 & 28.211 \\
\hline $\mathrm{p}>$ chi2 & $<0.001$ & $<0.001$ & 0.005 \\
\hline
\end{tabular}

Notes: This Table reports marginal effects from random-effects logit regressions with robust standard errors clustered at the subject level in parentheses. In all models, the independent variables are the same as those included in Table 2, except the variables coding the difference between the subject's and his opponent's random numbers since subjects have no information about either their own (Opp-condition) or their opponent's number (Self-condition). The regressions exclude the observations in which the subject's own random number is 5 in the Self-condition and those in which the opponent's random number is -5 in the Opp-condition. In model (2) one subject has been excluded: this subject misreported non-selfishly in three periods and selfish misreporting was impossible in three other periods (the opponent's random number was equal to -5$)$. ${ }^{* * *}$ indicate significance at the $1 \%$ level, ${ }^{* *}$ at the $5 \%$ level, and $*$ at the $10 \%$ level. 
Table B.5: Determinants of the reported random number in the Identity-No-Info and the Identity-No-Scrutiny treatments

\begin{tabular}{|c|c|c|c|c|}
\hline \multirow{2}{*}{$\begin{array}{l}\text { Dependent variable: } \\
\text { Reported random number }\end{array}$} & \multirow{2}{*}{$\begin{array}{l}\text { Both treatments } \\
\text { Both conditions } \\
\text { (1) }\end{array}$} & \multicolumn{3}{|c|}{ Identity-No-Scrutiny treatment } \\
\hline & & $\begin{array}{l}\text { Both conditions } \\
\text { (2) }\end{array}$ & $\begin{array}{l}\text { Opp-condition } \\
\text { (3) }\end{array}$ & $\begin{array}{c}\text { Self-condition } \\
\text { (4) }\end{array}$ \\
\hline Identity-No-Scrutiny treatment & $\begin{array}{c}0.986^{* * *} \\
(0.280)\end{array}$ & - & - & - \\
\hline In-group opponent & $\begin{array}{l}-0.076 \\
(0.096)\end{array}$ & $\begin{array}{c}-0.003 \\
(0.140)\end{array}$ & $\begin{array}{c}0.191 \\
(0.184)\end{array}$ & $\begin{array}{c}0.053 \\
(0.179)\end{array}$ \\
\hline Self-condition & $\begin{array}{c}0.587^{* * *} \\
(0.097)\end{array}$ & $\begin{array}{c}1.112^{* * *} \\
(0.141)\end{array}$ & - & - \\
\hline Subscore $_{i, t}$ & $\begin{array}{l}0.104 \\
(0.047)\end{array}$ & $\begin{array}{l}-0.046 \\
(0.068)\end{array}$ & $\begin{array}{c}0.184^{* *} \\
(0.092)\end{array}$ & $(0.085)$ \\
\hline Tie: subscore $_{i, t}=$ subscore $_{j, t}$ & $\begin{array}{c}0.013 \\
(0.156)\end{array}$ & $\begin{array}{l}-0.005 \\
(0.219)\end{array}$ & $\begin{array}{c}0.063 \\
(0.280)\end{array}$ & $\begin{array}{c}0.008 \\
(0.294)\end{array}$ \\
\hline $\operatorname{Max}\left\{0\right.$, subscore $_{i, t}-$ subscore $\left._{j, t}\right\}$ & $\begin{array}{l}-0.042 \\
(0.048)\end{array}$ & $\begin{array}{l}-0.085 \\
(0.061)\end{array}$ & $\begin{array}{c}0.208^{* * *} \\
(0.078)\end{array}$ & $\begin{array}{l}-0.031 \\
(0.083)\end{array}$ \\
\hline $\operatorname{Max}\left\{0\right.$, subscore $_{j, t}-$ subscore $\left._{i, t}\right\}$ & $\begin{array}{l}-0.013 \\
(0.056)\end{array}$ & $\begin{array}{l}-0.018 \\
(0.078)\end{array}$ & $\begin{array}{c}0.063 \\
(0.101)\end{array}$ & $\begin{array}{c}0.001 \\
(0.102)\end{array}$ \\
\hline Period & $\begin{array}{c}0.009 \\
(0.051)\end{array}$ & $\begin{array}{l}-0.011 \\
(0.073)\end{array}$ & $\begin{array}{l}-0.220^{*} \\
(0.126)\end{array}$ & $\begin{array}{l}-0.053 \\
(0.087)\end{array}$ \\
\hline Period squared & $\begin{array}{c}0.002 \\
(0.003)\end{array}$ & $\begin{array}{c}0.002 \\
(0.004)\end{array}$ & $\begin{array}{c}0.008 \\
(0.006)\end{array}$ & $\begin{array}{c}0.003 \\
(0.005)\end{array}$ \\
\hline SVO Angle & $\begin{array}{c}0.007 \\
(0.008)\end{array}$ & $\begin{array}{l}0.018^{*} \\
(0.011)\end{array}$ & $\begin{array}{l}-0.029^{*} \\
(0.016)\end{array}$ & $\begin{array}{c}0.007 \\
(0.010)\end{array}$ \\
\hline Male & $\begin{array}{l}0.529^{*} \\
(0.279)\end{array}$ & $\begin{array}{c}0.342 \\
(0.344)\end{array}$ & $\begin{array}{l}-0.672 \\
(0.509)\end{array}$ & $\begin{array}{c}0.038 \\
(0.324)\end{array}$ \\
\hline Other individual characteristics & Yes & Yes & Yes & Yes \\
\hline Number of observations & 3106 & 1664 & 832 & 832 \\
\hline Wald Chi2 & 108.987 & 81.113 & 47.258 & 19.403 \\
\hline $\mathrm{p}>\operatorname{chi} 2$ & $<0.001$ & $<0.001$ & $<0.001$ & 0.054 \\
\hline
\end{tabular}

Notes: This Table reports marginal effects from random-effects Tobit regressions with standard errors in parentheses. Model (1) pools the Self- and Opp-conditions and the Identity-No-Info and Identity-No-Scrutiny treatments. Models (2) to (4) include only the Identity-No-Scrutiny treatment with model (2) pooling both conditions, model (3) including only the Opp-condition, and model (5) only the Self-condition. To pool the reported numbers from both conditions in models (1) and (2), the dependent variable takes the value of the reported number in the Self-condition and the value of the reported number in the Opp-condition multiplied by -1 . In contrast in model (3), the dependent variable takes the actual value (not multiplied by -1 ) of the number reported for the opponent. In all models, the independent variables are the same as those in Table 2 , except for variables relative to the random numbers since in the Identity-No-Scrutiny treatment we ignore the true random numbers. $* * *$ indicate significance at the $1 \%$ level, ** at the $5 \%$ level, and $*$ at the $10 \%$ level. 


\section{Figures}

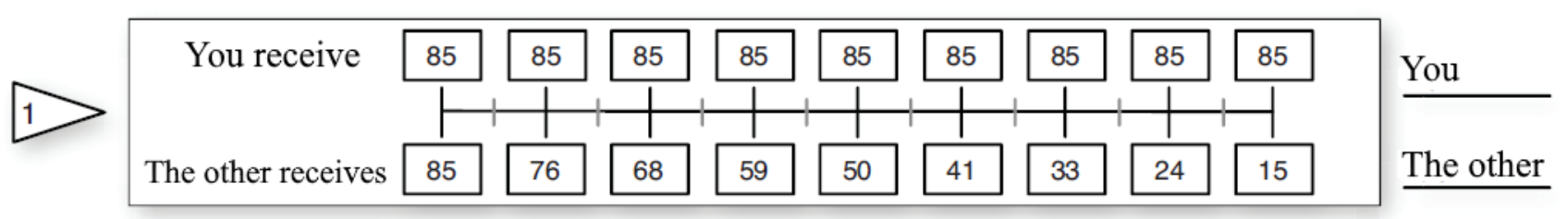

Figure C.1: First decision in the SVO test

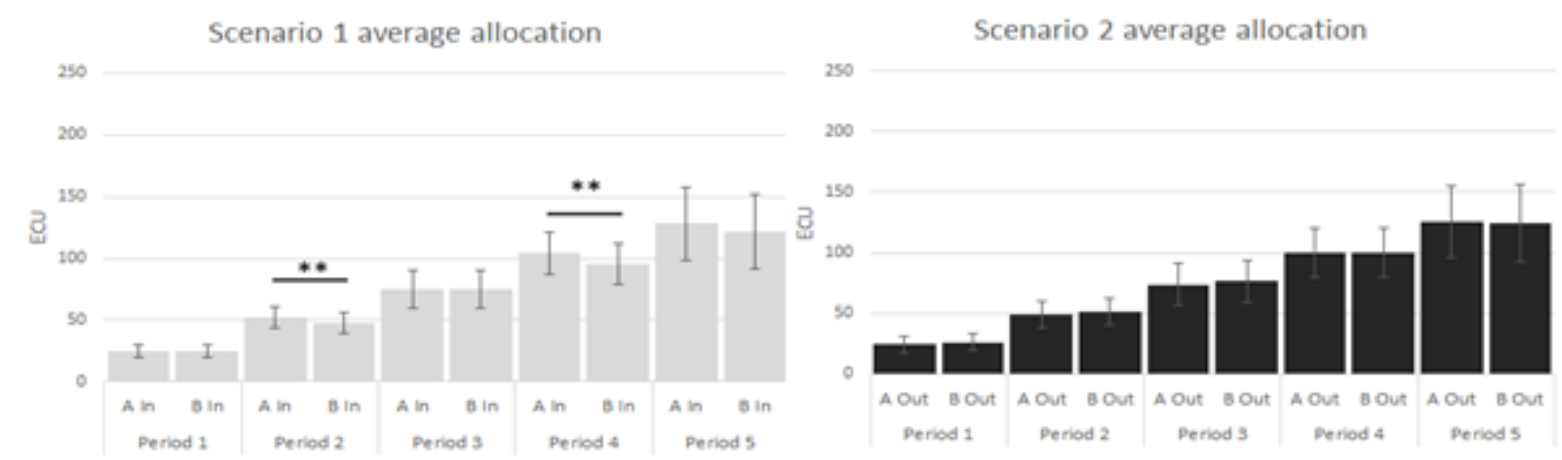

Figure C.2: Average allocation in ECUs as a third party in scenario 1 (left panel) and scenario 2 (right panel), by period (stage 3 of the group identity induction procedure)

Notes: "In" stands for in-group and "Out" for out-group. In scenario 3, person A is an in-group member and $\mathrm{B}$ is an out-group member. ${ }^{* * *}$ indicate significance at the $1 \%$ level in two-sided pair-wise t-tests. 


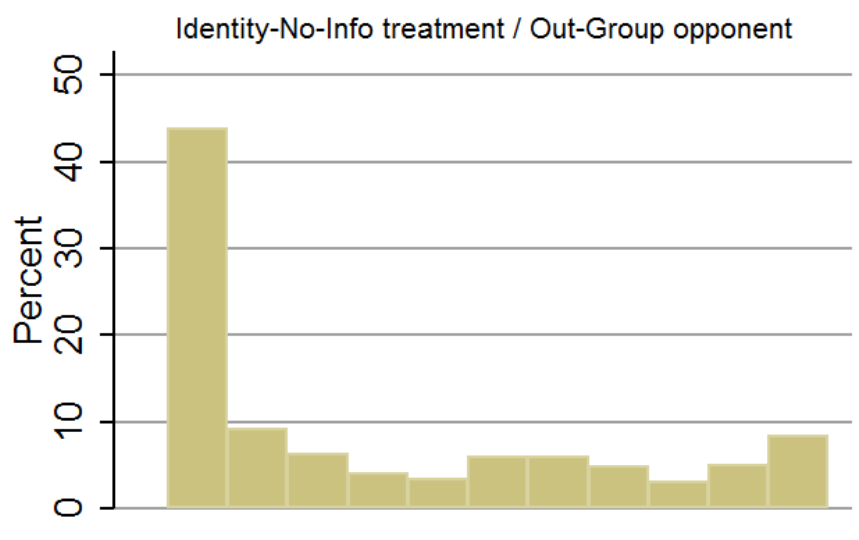

Identity-No-Scrutiny treatment / Out-Group opponent

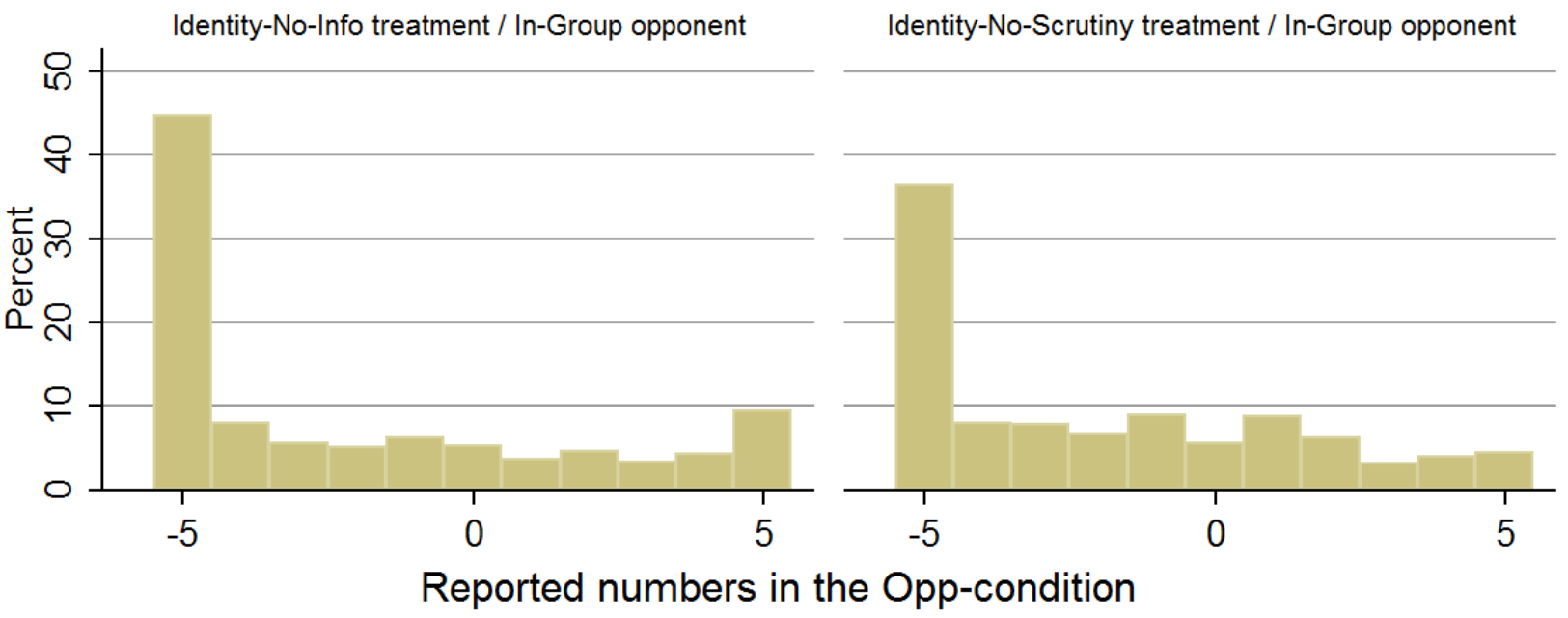

Figure C.3: Distribution of the reported numbers in the Opp-condition, by treatment and identity matching 


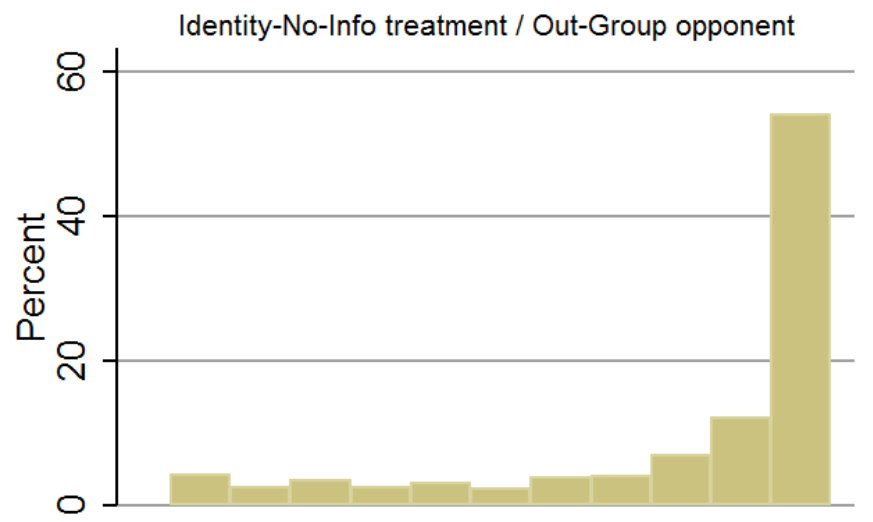

Identity-No-Scrutiny treatment / Out-Group opponent

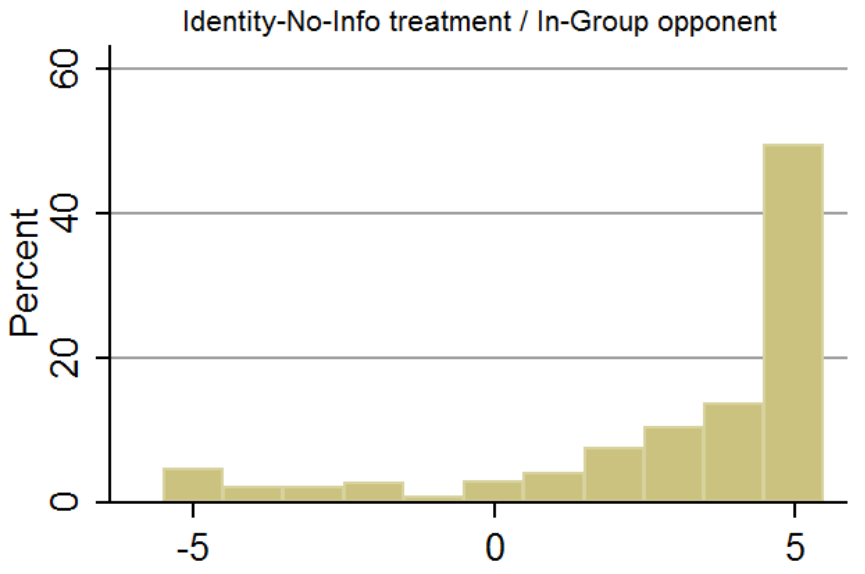

Identity-No-Scrutiny treatment / In-Group opponent

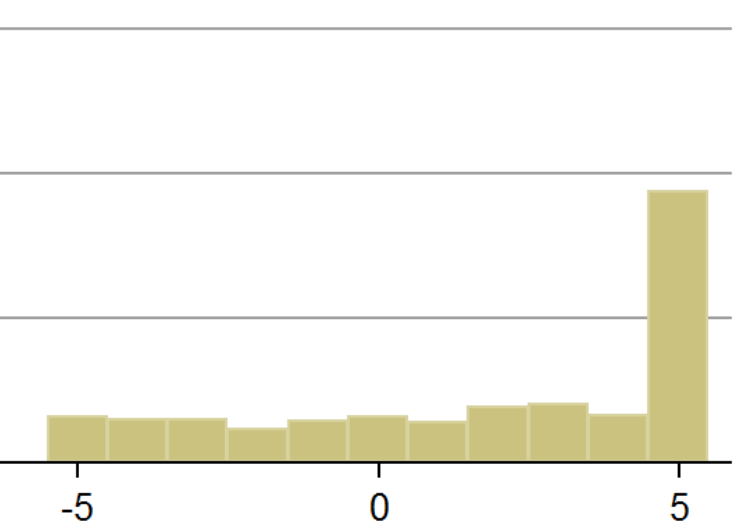

Reported numbers in the Self-condition

Figure C.4: Distribution of the reported numbers in the Self-condition, by treatment and identity matching 